ARTICLE

https://doi.org/10.1038/s41467-021-24930-y

\title{
Toxin import through the antibiotic efflux channel TolC
}

Nicholas G. Housden (10) 1,3, Melissa N. Webby (1) 1,3, Edward D. Lowe1, Tarick J. El-Baba², Renata Kaminska1, Christina Redfield (10) ${ }^{1}$, Carol V. Robinson (1) ${ }^{2} \&$ Colin Kleanthous (1) ${ }^{1 凶}$

Bacteria often secrete diffusible protein toxins (bacteriocins) to kill bystander cells during interbacterial competition. Here, we use biochemical, biophysical and structural analyses to show how a bacteriocin exploits TolC, a major outer-membrane antibiotic efflux channel in Gram-negative bacteria, to transport itself across the outer membrane of target cells. Klebicin $\mathrm{C}(\mathrm{KlebC})$, a rRNase toxin produced by Klebsiella pneumoniae, binds TolC of a related species (K. quasipneumoniae) with high affinity through an $\mathrm{N}$-terminal, elongated helical hairpin domain common amongst bacteriocins. The KlebC helical hairpin opens like a switchblade to bind TolC. A cryo-EM structure of this partially translocated state, at $3.1 \AA$ resolution, reveals that $\mathrm{KlebC}$ associates along the length of the TolC channel. Thereafter, the unstructured $\mathrm{N}$ terminus of KlebC protrudes beyond the TolC iris, presenting a TonB-box sequence to the periplasm. Association with proton-motive force-linked TonB in the inner membrane drives toxin import through the channel. Finally, we demonstrate that KlebC binding to TolC blocks drug efflux from bacteria. Our results indicate that TolC, in addition to its known role in antibiotic export, can function as a protein import channel for bacteriocins.

\footnotetext{
${ }^{1}$ Department of Biochemistry, University of Oxford, Oxford, UK. ${ }^{2}$ Physical and Theoretical Chemistry Laboratory, Department of Chemistry, University of

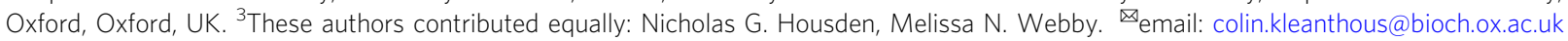


T he outer membrane $(\mathrm{OM})$ of Gram-negative bacteria is comprised of a phospholipid inner leaflet and an outer leaflet of lipopolysaccharides cross-linked by chelated divalent cations. This asymmetric membrane forms a robust structure that stabilises the cell envelope and secures bacterial survival in challenging environments. The $\mathrm{OM}$ is also a virulence factor in pathogens and, through its exclusion of both hydrophobic and hydrophilic compounds, a major component of antibiotic resistance in Gram-negative bacteria ${ }^{1}$. Small $(<700 \mathrm{Da})$ antibiotics can nevertheless cross the OM through porins such as $\mathrm{OmpF}$ and OmpC that pepper the bacterial surface ${ }^{2}$. To counter the effects of antibiotics, bacteria adapt by reducing the permeability of the OM, inactivating or hydrolysing the antibiotic or actively expelling the drug from the cell. TolC is one of the most prevalent drug efflux channels in bacteria and is frequently associated with multidrug resistance ${ }^{3}$. TolC also forms the exit tunnel for type I secretion of hemolysin, a pore-forming toxin that lyses red blood cells ${ }^{4}$.

Bacteriocins are diffusible peptide or protein antimicrobial toxins deployed by Gram-positive and Gram-negative bacteria to kill their neighbours in the unremitting warfare between and within bacterial populations ${ }^{5}$. Protein bacteriocins (herein referred to simply as bacteriocins) are weaponry often used by Enterobacteriaceae and Pseudomonaceae that are living in ecological niches as diverse as soil, plants, animals and humans ${ }^{6}$. Bacteriocin genes are often associated with virulence factors, suggesting they help pathogens become established during pathogenesis 7 . Bacteriocins tend to be species-selective, killing only closely related bacteria due to the specific protein-protein interactions involved in binding surface receptors and translocating into the cell. Their import is driven by the proton-motive force (PMF) in conjunction with either the Tol (group A bacteriocins) or the Ton (group B bacteriocins) systems ${ }^{8}$. The physiological roles of the Tol (also known as Tol-Pal) and Ton systems are to stabilise the OM during cell division ${ }^{9}$ and transport nutrients through TonB-dependent transporters $(\mathrm{TBDTs})^{10}$, respectively. These functions are parasitized by bacteriocins to catalyse their transfer across the OM. Following internalisation, cell death ensues through the delivery of a cytotoxic domain located at the C-terminus of the toxin that degrades DNA, rRNA or tRNA in the cytoplasm, depolarises the inner membrane or cleaves peptidoglycan precursors in the periplasm. Bacteriocinproducing bacteria are immune to the specific action of their toxin by virtue of a small immunity protein that binds and inactivates the toxin and which, in the case of nucleases, is jettisoned during import ${ }^{11,12}$.

Much is known about the associations of bacteriocins with OM receptors, translocator proteins and components of the Tol or Ton systems, but not how they cross the OM since no bacteriocin has yet been trapped and structurally characterised within its OM translocon. Nevertheless, the routes taken by these toxins to cross the $\mathrm{OM}$ are beginning to be mapped out. For example, photoactivatable cross-linking studies have shown that the group B bacteriocin pyocin S2 (PyoS2), a nuclease deployed by Pseudomonas aeruginosa, translocates directly through a TBDT ${ }^{13}$. Following binding to the common polysaccharide antigen ${ }^{14}$, PyoS2 associates with the pyoverdine transporter, FpvAI. Import through FpvAI is a two-step process; both steps are driven by the $\mathrm{PMF}$, transduced to the OM by TonB in conjunction with its inner membrane stator protein partners, ExbB and ExbD. In the first step, the plug domain that normally occludes the central channel of FpvAI is partially opened by TonB. This occurs by TonB mechanically deforming the plug through its association with a TonB-box epitope at the N-terminus of FpvAI in the periplasm. In the second step, PyoS2 delivers its own TonB box, in the form of a disordered linear epitope, through the now-open
FpvAI channel that engages TonB and enables the toxin to be pulled unfolded through the transporter.

In this work, we define the import pathway for a family of group B bacteriocins found amongst the Enterobacteriaceae. Focusing on the $60-\mathrm{kDa}$ rRNase bacteriocin klebicin C (KlebC) from Klebsiella pneumoniae, we show how KlebC exploits the antibiotic efflux channel TolC to transport itself across the OM. As part of this work, we structurally characterise a trapped complex formed between KlebC and the TolC translocation channel.

\section{Results}

Identification of the KlebC outer-membrane receptor. Onethird of all K. pneumoniae strains recently surveyed encode one or more nuclease bacteriocins which, despite low-sequence identity, have similar domain organisation to that seen in other bacterial species, principally Escherichia coli, Salmonella enterica, Serratia marcescens, Shigella sonnei and Enterobacter cloacae ${ }^{7}$. Nuclease bacteriocins in these species typically have disordered $\mathrm{N}$-termini followed by one or more structured domains involved in import and a nuclease domain at the C-terminus. This work focuses on KlebC, a little-studied rRNase bacteriocin. rRNase bacteriocins kill target cells by cleaving a single phosphodiester bond within the ribosomal A-site of the 70S ribosome. While the mechanism by which bacteriocin rRNase domains inhibit protein synthesis is well-understood ${ }^{15}$, it is largely unknown how such domains cross the OM. Hence, we set out to define the KlebC import mechanism by first identifying its OM receptor and/or translocator by affinity purification, using an approach similar to that used to define the OM translocon for the E. coli-specific bacteriocin, colicin $\mathrm{E}^{16}$. Initial attempts to express $\mathrm{KlebC}$ as a heterodimeric complex with its immunity protein and a Cterminal histidine tag-an approach used previously for nuclease colicins ${ }^{17}$-was hampered by toxicity. This was circumvented through the construction of a KlebC-E9 DNase hybrid, in which the highly toxic rRNase domain of KlebC was replaced by the DNase domain of colicin E9 (ColE9) (Supplementary Fig. 1a). This hybrid protein was readily expressed and purified as a heterodimeric complex via a $\mathrm{C}$-terminal His tag on its immunity protein Im9. The isolated hybrid protein killed Klebsiella pneumoniae, Klebsiella varricola and Klebsiella quasipneumoniae, in addition to possessing significant activity against $E$. coli (Supplementary Fig. 1b). These experiments demonstrated that the remaining KlebC domains harbour all the information necessary to transport the nuclease into bacteria. Importantly, the cytotoxicity of KlebC-E9 DNase hybrid (hereafter referred to as KlebC) against E. coli allowed us to test select stains from the Keio E. coli knockout collection ${ }^{18}$ as a means of identifying important components of the import pathway. Hence, KlebC was shown to be a TonB-dependent, group $\mathrm{B}$ bacteriocin since the ton $B$ knockout was completely resistant to its action whereas the tolA deletion remained sensitive (Supplementary Fig. 1b).

We performed a series of pull-down assays to identify KlebC OM binding partners. Purified KlebC was added to cultures of $K$. quasipneumoniae, followed by lysis, outer-membrane purification, detergent extraction, and nickel affinity chromatography. Imidazole eluate from the nickel affinity column was analysed by SDS-PAGE, revealing three prominent bands, which were identified by peptide mass fingerprinting (Supplementary Fig. 1c). The $70 \mathrm{kDa}$ band was found to be the bait protein KlebC, and the $50 \mathrm{kDa}$ band was identified as the OM efflux channel TolC (45 peptides, $92.8 \%$ sequence coverage). The $34 \mathrm{kDa}$ band contained peptides from degraded bait protein in addition to 7 peptides from the OM protein OmpA (22.8\% sequence coverage). We further investigated the roles of TolC and OmpA in KlebC uptake 
using BW25113 ompA and BW25113 tolC knockout strains (Supplementary Fig. 1d). The former showed no impact on KlebC toxicity suggesting it to be a contaminant due to its high natural abundance, whilst the latter was resistant. Although TolC was critical for KlebC toxicity its inner membrane partners AcrA and $A c r B$, which energise drug efflux from bacteria ${ }^{19}$, were not involved in KlebC function (Supplementary Fig. 1d). While several colicins (E1, 5 and 10) are known to kill E. coli in a TolCdependent manner ${ }^{20-22}$ and share sequence identity (55\%) with the N-terminal domain of $\mathrm{KlebC}$, it remains unclear what role TolC plays in the import mechanism. Indeed, in the case of ColE1, it is thought that TolC simply constitutes a docking site prior to OM translocation ${ }^{23}$. We conclude that KlebC is a TolCdependent, group B bacteriocin that kills $K$. pneumoniae and closely related species. Furthermore, an N-terminal domain implicated in KlebC uptake via TolC by an ill-defined mechanism is conserved amongst other TolC-utilising bacteriocins targeting different species (Supplementary Fig. 1e). Finally, we identified a TonB-box motif in KlebC $\left(\mathrm{M}^{16} \mathrm{VSLG}^{20}\right)$ the mutation of which abolished toxicity (Supplementary Fig. 1f). This result is consistent with KlebC contacting TonB during import, which is a requirement for all group $B$ bacteriocins ${ }^{5}$.

Structure and binding mechanism of the TolC-binding domain of KlebC. We next set out to delineate the TolC-binding region of KlebC and determine its structure; no structure has yet been reported for any TolC-binding domain. Secondary structure predictions for KlebC suggest the first 53 residues are disordered and are followed by a region of 218 residues with high $\alpha$-helical propensity, with a break in helicity between residues 251 and 255. This region also encompassed sequence related to other TolCdependent bacteriocins (Supplementary Fig. 1e). Three constructs encoding residues 1-271, 1-254 and 51-254 were cloned with Cterminal $\mathrm{His}_{6}$-tags and their ability to bind $\mathrm{K}$. quasipneumoniae TolC was assessed using analytical gel-filtration chromatography. TolC eluted at a volume of $12.0 \mathrm{ml}$, whilst the elution peaks of TolC in the presence of $\mathrm{KlebC}_{1-271}, \mathrm{KlebC}_{1-254}$ and $\mathrm{KlebC}_{51-254}$ shifted to $10.6,10.8$, and $11 \mathrm{ml}$, respectively, consistent with complex formation (Supplementary Fig. 2). Crystallisation screens were focused solely on $\mathrm{KlebC}_{51-254}$ since this construct retained TolC-binding activity (similar to $\mathrm{KlebC}_{1-271}$ ) whilst removing the putative disordered region at the $\mathrm{N}$-terminus. Crystals of selenomethionine-labelled $\mathrm{KlebC}_{51-254}$ were obtained in the $\mathrm{P} 3_{2} 21$ space group. The resulting structure, solved by single-wavelength anomalous diffraction to a resolution of $1.9 \AA$, revealed a helical hairpin spanning $150 \AA$ (Fig. 1a). Modelled density spanned Lys62 to Leu255, with residues 64-131 forming helix 1 of the hairpin and helix 2 containing residues 145-248. The lack of density for residues 51-61 suggest that the disorder predicted for the first 50 residues may extend further into the molecule. We explored this possibility with heteronuclear NMR experiments and found that indeed the first 60 residues of KlebC are disordered in solution (Supplementary Fig. 3). Residues 62-73 in the structured hairpin domain are weakly helical, as evidenced by peptide bond characteristics atypical of standard $\alpha$-helix.

We next investigated how the helical-hairpin domain of KlebC bound TolC using different biophysical approaches and domain constructs with or without the disordered region at the $\mathrm{N}$ terminus. Isothermal titration calorimetry (ITC) demonstrated that a single molecule of $\mathrm{KlebC}_{1-254}$ bound the TolC trimer $(N=$ $0.90 \pm 0.03)$ with a $K_{\mathrm{d}}$ of $35 \pm 7 \mathrm{nM}$ through an entropically driven, endothermic interaction (Fig. 1b). Truncated KlebC ${ }_{51-254}$ bound TolC with an affinity approximately tenfold weaker $\left(K_{\mathrm{d}}=\right.$ $368 \pm 16 \mathrm{nM}, \quad N=1.34 \pm 0.12$ ) (Fig. 1b), demonstrating that although disordered, the $\mathrm{N}$-terminal region of KlebC plays a role in the TolC interaction. The binding kinetics of KlebC for TolC were also investigated, using intrinsic fluorescence and capitalising on the $12 \%$ enhancement in tryptophan emission fluorescence $\left(\lambda_{\text {ex }}, 295 \mathrm{~nm} / \lambda_{\text {em }}, 340 \mathrm{~nm}\right)$ for the complex. Pre-equilibrium fluorescence measurements revealed binding to be very slow, suggestive of a single-step process occurring with a bimolecular association rate constant $\left(k_{\text {on }}\right)$ of $1.9 \pm 0.1 \times 10^{3} \mathrm{M}^{-1} \mathrm{~s}^{-1}$ (Fig. $1 \mathrm{c}$ ). Having established the $K_{\mathrm{d}}$ for the complex by ITC, the dissociation rate constant $\left(k_{\text {off }}\right)$, which was too slow to be measured (insert, Fig. 1c), was estimated to be $\sim 5 \times 10^{-5} \mathrm{~s}^{-1}$, assuming the kinetically determined $K_{\mathrm{d}}=k_{\text {off }} / k_{\text {on }}$. Typical protein-protein interactions have association rate constants $>10^{5} \mathrm{M}^{-1} \mathrm{~s}^{-1}$. Ultra-slow association, such as that observed for the $\mathrm{KlebC}_{1-254}$-TolC complex, is often indicative of gross conformational changes accompanying complex formation ${ }^{24}$.

We hypothesised that the kinetics of association and thermodynamic signature of KlebC-TolC complex formation were the results of the KlebC helical-hairpin unfurling. We tested this hypothesis in two ways. The first approach involved introducing disulphide bond crosslinks across the helical hairpin of KlebC which could prevent the hairpin from opening. Using disulphideby-design $^{25}$, two interhelical disulphide bonds were engineered (L86C, L198C and A107C, Y177C; Fig. 1a) to lock the helical hairpin in the conformation observed in the crystal structure. The introduction of either of these disulphide bonds into KlebC resulted in a toxin active in its reduced form, but inactive in the oxidised state (Fig. 1d). To determine if the disulphides within KlebC had inactivated the toxin by preventing translocation following receptor binding, or prevented receptor binding itself, the disulphides were engineered into $\mathrm{KlebC}_{1-254}$ and complex formation with TolC investigated by analytical gel-filtration chromatography. In their reduced forms, both L86C, L198C KlebC $_{1-254}$ and $\mathrm{A} 107 \mathrm{C}, \mathrm{Y} 177 \mathrm{C} \mathrm{KlebC}_{1-254}$ bound TolC, but in their oxidised states neither protein could bind TolC (Fig. 1e). These experiments indicate that TolC binding requires the helical hairpin to undergo a gross conformational change from that observed in the crystal structure.

We applied a second approach using a FRET-based assay to determine whether the helical hairpin of $\mathrm{KlebC}_{1-254}$ unfurled on association with TolC. The TolC-binding domain of KlebC contains a single tryptophan (W81) located within helix 1. A cysteine was introduced into helix 2 of $\mathrm{KlebC}_{1-254}$ (Q204C), in close proximity to W81 allowing for labelling with 5-((() iodoacetyl)amino)ethyl)amino)naphthalene-1-sulfonic acid (IAEDANS) and the creation of a Trp-AEDANS FRET pair that was used to monitor the conformation of the hairpin. Using an excitation wavelength of $280 \mathrm{~nm}$, and in the absence of TolC, Q204CAEDANS KlebC $_{1-254}$ gave a Trp-to-AEDANS FRET signal at $490 \mathrm{~nm}$, which upon addition of equimolar TolC trimer decreased by $77 \%$ (Fig. 1f), which is consistent with the hairpin unfurling during complex formation. Loss of the Trp-toAEDANS FRET signal upon TolC binding was further investigated under pre-equilibrium conditions. Experiments performed under pseudo-first-order conditions, with either Q204C AEDANS KlebC $_{1-254}$ or TolC in excess resulted in a single-phase fluorescence decrease (Supplementary Fig. 4), which was fitted to a single exponential equation to give $k_{\text {app. }}$. From the variation in $k_{\text {app }}$ with protein concentration, association rate constants of $6.7 \pm 0.2 \times 10^{3} \mathrm{M}^{-1} \mathrm{~s}^{-1}$ and $2.9 \pm 0.1 \times 10^{3} \mathrm{M}^{-1} \mathrm{~s}^{-1}$ were calculated, with TolC and Q204C ${ }^{\text {AEDANS }} \mathrm{KlebC}_{1-254}$ in excess, respectively. Notwithstanding the slow association rate constant, the requirement of the TolC-binding domain of KlebC to undergo a significant conformational rearrangement prior to binding does not appear to be rate-limiting. This interpretation is suggested by the observation that with either component in excess a single-phase fluorescence change is observed and that the 
a
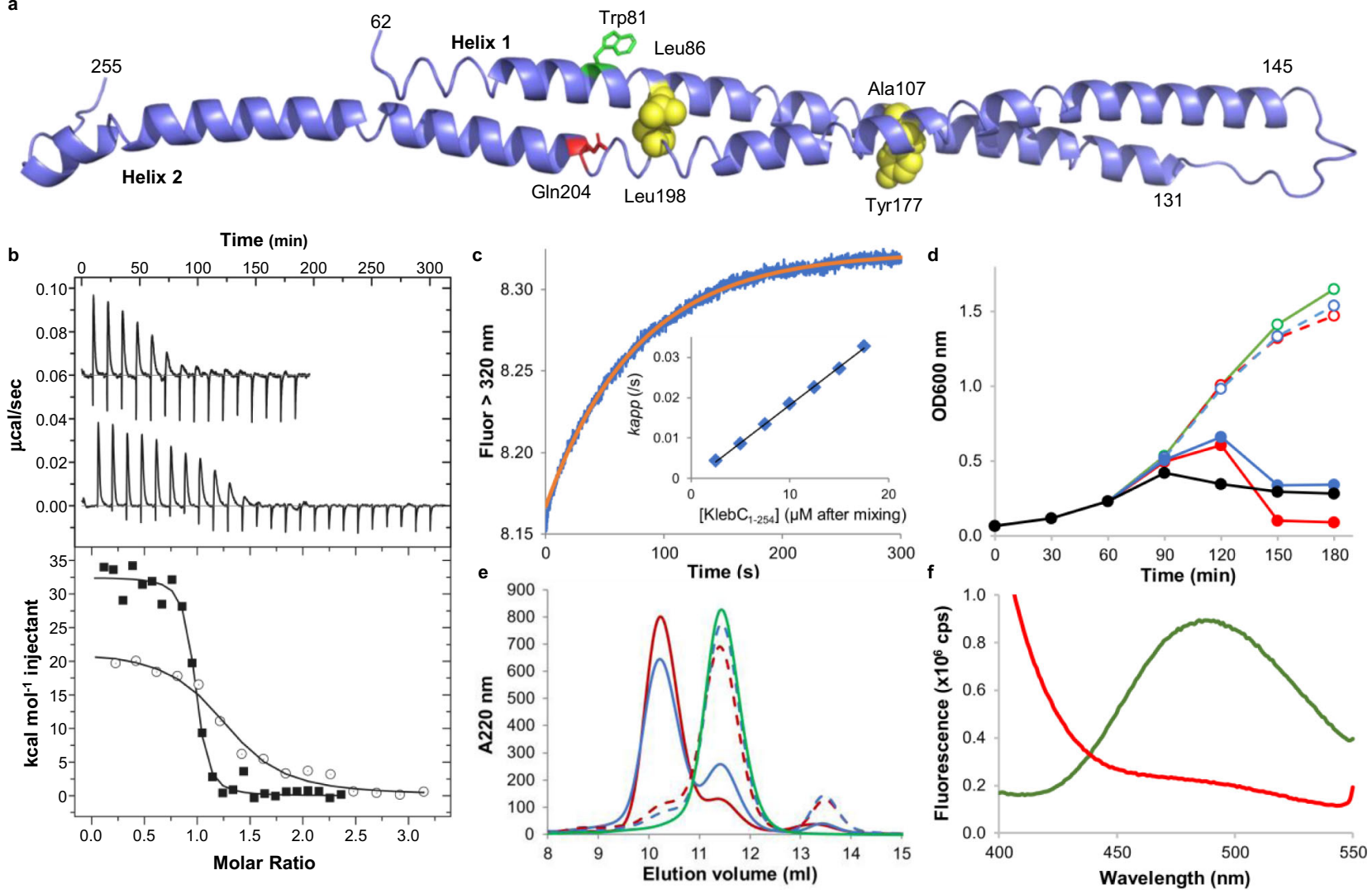

Fig. 1 Structure of the KlebC-TolC-binding domain and its binding to KqTolC. a Cartoon representation of the KlebC $51-254$ TolC-binding domain crystal structure. Leu86, Ala107, Tyr177 and Leu198, mutated to form disulphide bonds are shown as yellow spheres. Side chains of FRET pair Trp81 (green sticks)

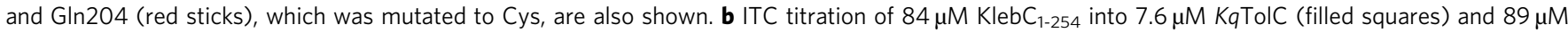
$\mathrm{KlebC}_{51-254}$ into $5.9 \mu \mathrm{M} \mathrm{KqTolC}$ (offset by $0.06 \mu \mathrm{cal} \mathrm{s}{ }^{-1}$ in top panel and open circles in bottom panel). Data were fitted to a one set of sites fit to give $K_{\mathrm{d}}=$ $35 \pm 7 \mathrm{nM}, N=0.90 \pm 0.03$ binding sites per TolC trimer and $\Delta \mathrm{H} 30.6 \pm 2.6 \mathrm{kcal} \mathrm{mol}^{-1}$ and $K_{\mathrm{d}}=368 \pm 16 \mathrm{nM}, N=1.34 \pm 0.12$ binding sites per TolC trimer and $\Delta H 20.8 \pm 1.0 \mathrm{kcal} \mathrm{mol}^{-1}$ for $\mathrm{KlebC}_{1-254}$ and $\mathrm{KlebC}_{51-254}$, respectively. Typical traces are shown, values are averages of duplicate experiments. $\mathbf{c}$ Pre-

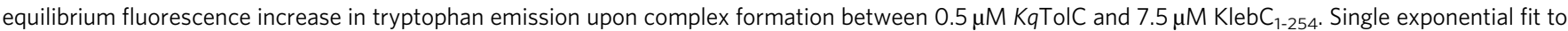
the data to determine $k_{\text {app }}$ is shown in red. Inset, Dependence of $k_{\text {app }}$ on $\mathrm{KlebC}_{1-254}$ concentration. Data are averages of duplicate experiments fitted to a straight line, the gradient of which gives the association rate constant, $1.9 \pm 0.1 \times 10^{3} \mathrm{M}^{-1} \mathrm{~s}^{-1}$. d Liquid growth curves of $K$. quasipneumoniae Qmp M1-977, with the addition of KlebC-E9 DNase (black), A107C, Y177C KlebC-E9 DNase (reduced, solid red; oxidised, dashed red), L86C, L198C KlebC-E9 DNase (reduced, solid blue; oxidised, dashed blue), or no KlebC-E9 DNase (green), added after $60 \mathrm{~min}$. Data shown are from one representative experiment out of three biological repeats. e In total, $200 \mu \mathrm{K}$ KTolC (green), KqTolC + L86C, L198C KlebC $1-254$ (reduced, solid blue; oxidised, dashed blue), and KqTolC + A107C, Y177C KlebC $1-254$ (reduced, solid red; oxidised, dashed red) were loaded onto a 10/300 S200 column. f Fluorescence emission of $1 \mu \mathrm{M}$ Q204CAEDANS KlebC $_{1-254}$ in the absence (green) and presence (red) of $1 \mu \mathrm{M} \mathrm{KqTolC}$. $\lambda_{\mathrm{Ex}}=280 \mathrm{~nm}$, slit widths $=2 \mathrm{~nm}$.

observed association rate constant in the presence of excess TolC was only 2.3-fold faster than when Q204C AEDANS $\mathrm{KlebC}_{1-254}$ was in excess. Hence, our kinetic data suggest that a significant fraction of $\mathrm{KlebC}_{1-254}$ in solution is in a binding-competent form ( $40 \%)$. Taken together, these data demonstrate that the $\mathrm{N}$ terminal helical-hairpin domain of KlebC must unfurl in order to bind TolC, that unfurling is not rate-limiting for TolC binding and that this conformational change is a requirement for TolCmediated killing of bacterial cells by KlebC.

Structure of Klebsiella quasipneumoniae TolC and its complex with $\mathrm{KlebC}_{\mathbf{1 - 2 5 4}}$. K. quasipneumoniae Qmp M1-977 is a KlebC susceptible strain in which TolC $(\mathrm{KqTolC})$ shares $83 \%$ sequence identity with E. coli K-12 TolC. KqTolC was expressed and purified for single-particle cryo-EM studies to resolve the structure of the $K q$ TolC-KlebC ${ }_{1-254}$ complex. $K q$ TolC-KlebC $1-254$ was mixed in $\beta$-OG and transferred into amphipol A8-35 after which image processing resulted in the structure of $K$. quasipneumoniae TolC at a resolution of $3.4 \AA$ (Supplementary Figs. 5-7). However, this structure only resolved $\mathrm{KqTolC}$, which nevertheless served as a useful control. KqTolC is a $150-\mathrm{kDa}$ homotrimer comprised of $50-\mathrm{kDa}$ subunits, each contributing four $\beta$-strands to form a single 12-stranded $\beta$-barrel across the outer membrane. The remainder of each subunit adopts a helical structure forming an elongated channel. Whilst the $\beta$-barrel in the membrane is exposed to the extracellular environment the $\alpha$-helical segment of the protein forms an iris in the periplasm. The structure of $K q$ TolC differs from that of $E$. coli ${ }^{26}$ through a six-residue deletion in an extracellular loop extending from the $\beta$-barrel. The position of extracellular loops within the structure defines the accessible size of the $\beta$-barrel, creating a more open configuration in $K q$ TolC relative to E. coli TolC (Supplementary Fig. 7). Although some local distortions are observed at the iris where helices meet, none significantly alter the effective diameter of the iris (4-5 $\AA$ at its narrowest point).

The cryo-EM structure of the KqTolC-KlebC ${ }_{1-254}$ complex was eventually obtained following stabilisation of the complex by formaldehyde cross-linking prior to detergent exchange into amphipol A8-35 (Fig. 2). Initial processing of the micrographs produced a map with pseudo C3 symmetry, although no 


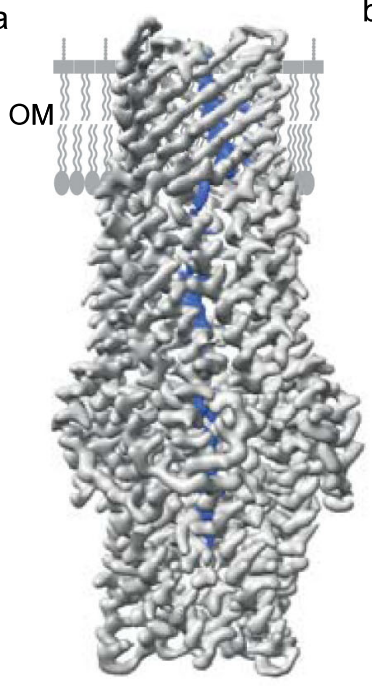

d

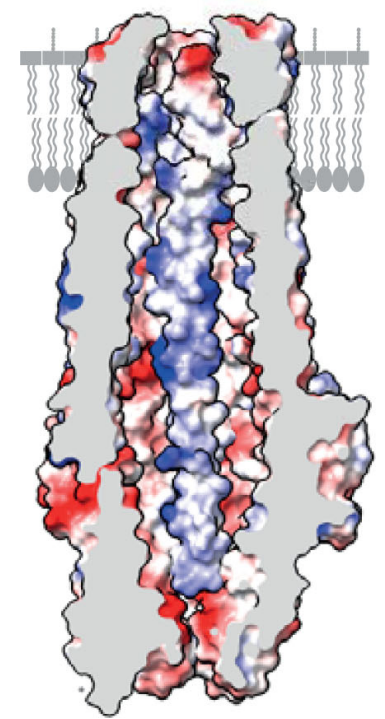

b

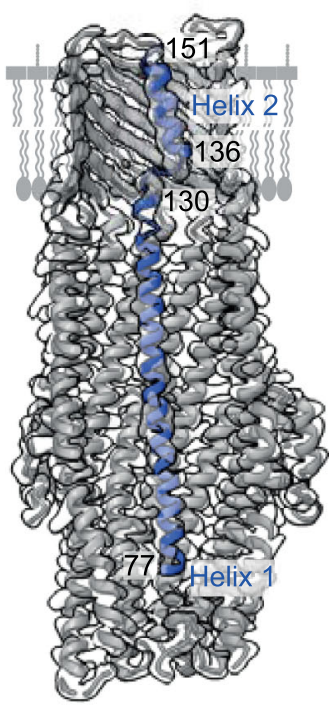

e

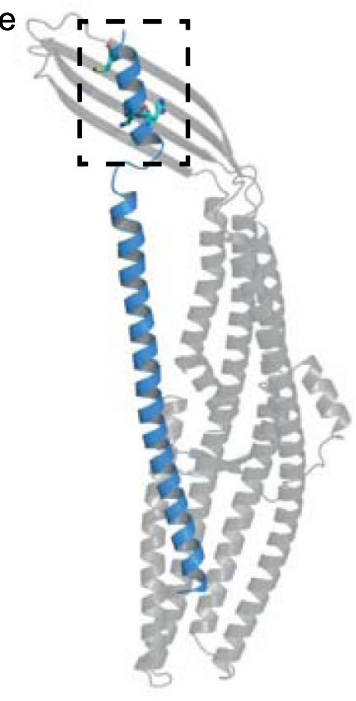

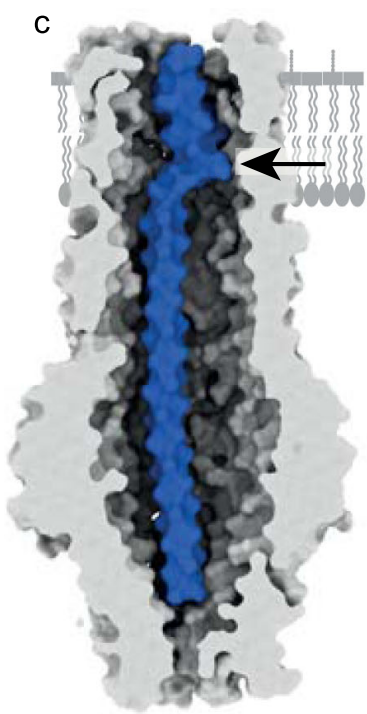
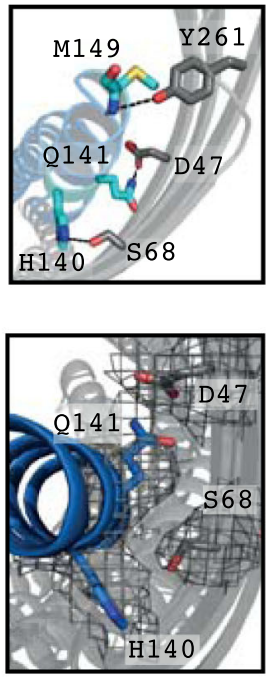

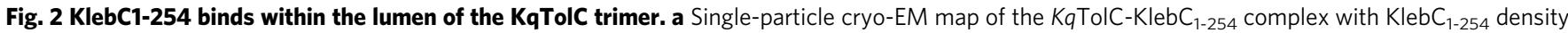

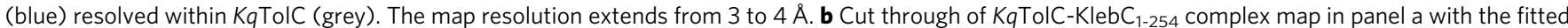

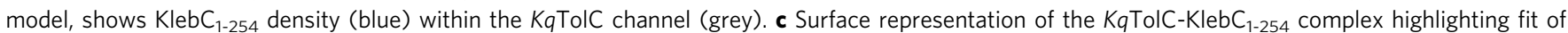

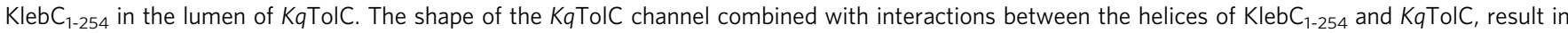
$\mathrm{KlebC}_{1-254}$ forming a kink (denoted by the arrow) in order to pass through the pore unobstructed. d Model of the electrostatic surface for the KqTolC$\mathrm{KlebC}_{1-254}$ complex (the protein sequence for helix 1 is depicted in place of polyalanine used to solve the structure), highlighting the charge matching between the two proteins. Electrostatics generated in chimera. e $\mathrm{KqTolC}$ chain C shown as a cartoon (grey) interacts with $\mathrm{KlebC}_{1-254}$ (blue cartoon) helix 2 . Insets show zoomed view of key interactions between $\mathrm{KqTolC}$ chain $\mathrm{C}$ (grey sticks) and $\mathrm{KlebC}_{1-254}$ (cyan sticks), which are localised predominantly to the $\mathrm{N}$-terminal end of helix 2. Cryo-EM map density for modelled residues is shown as inset bottom right.

symmetry was applied during processing (Supplementary Fig. 5). In this map, three copies of KlebC helix 2 were resolved within the TolC $\beta$-barrel, contrasting biophysical data that suggest one KlebC is bound per TolC trimer. To improve the map quality and further resolve KlebC density to get further insight into the binding mode, the amphipol shell surrounding the $\beta$-barrel domain of TolC was subtracted and C3 symmetry applied, increasing map resolution from 3.4 to $2.8 \AA$. Application of symmetry during processing then allowed for symmetry expansion of the dataset and subtraction of particles to give a single monomer, after which 3D sorting of particles revealed several classes where KlebC density was weakly apparent. A single class was further processed (see "Methods" and Supplementary Fig. 5) to produce the final $3.1 \AA$ map of the TolC trimer with both helix 1 and 2 of KlebC resolved (Fig. $2 \mathrm{a}-\mathrm{c}$ ). In the final model, density corresponding to helix 1 and the $\mathrm{N}$-terminal end of helix 2 of a single KlebC molecule span $109 \AA$ of the TolC lumen; the $\mathrm{N}$ terminal end of helix 1 is located near the periplasmic iris of TolC while helix 2 resides near the top within the outer-membrane $\beta$ barrel. The conformation of KlebC observed within the complex demonstrates unequivocally that the KlebC hairpin unfurls, forming a distorted kinked structure in which helix 1 is positioned against the $\alpha$-helical region of TolC, and residues 137-151 form helix 2 within the transmembrane $\beta$-barrel of TolC (Fig. 2a-c).

In the crystal structure of the $\mathrm{KlebC}_{51-254}$ isolated helical hairpin, residues Asp137 to Gln144 comprise the linker sequence between helix 1 and helix 2. By contrast, in the complex with $\mathrm{KqTolC}$ this region forms the N-terminal end of helix 2. This change in structure is accommodated by hydrogen bonding 
interactions between $\mathrm{KlebC}$ and $\mathrm{TolC}$. The TolC channel is highly electronegative while the region of KlebC that binds TolC is basic $(p I, 10)$. The modelled structure of the complex shows charge complementarity plays an important role in stabilising the complex since several localised regions of positive and negative charge are matched (Fig. 2d). The N-terminus of KlebC helix 1 is oriented such that it is proximal to both chain $\mathrm{A}$ and $\mathrm{C}$ of the TolC trimer towards the iris, whilst the C-terminus of helix 1 can solely interact with chain A where the helices of TolC meet the $\beta$ barrel strands at the inner leaflet of the OM. In contrast, helix 2 of KlebC packs against the $\beta$-barrel region of chain $\mathrm{C}$ with His 140 and Gln141, from within interhelical linker, now forming hydrogen bonds to Ser68 and Asp47 of TolC, respectively (Fig. 2e). Despite residing within the TolC lumen, several regions of KlebC do not come into contact with the channel due to the restricted flexibility of KlebC helix 1 . The unfurling of the $\mathrm{KlebC}_{1-254}$ helical hairpin required to bind TolC results in the loss of $1994 \AA^{2}$ buried accessible surface area between the two helices. This is compensated for in the complex with TolC by the burial of $2384 \AA^{2}$, predominantly through interactions with subunits $\mathrm{A}$ and C of TolC (1170 $\AA^{2}$ and $1120 \AA^{2}$, respectively).

In summary, we have structurally resolved a partially translocated state of KlebC, trapped within its receptor/translocator, TolC. The 150- $\AA$ long, N-terminal helical-hairpin domain of KlebC unfurls entirely in order to bind the lumen of TolC thereby positioning its $\mathrm{N}$-terminus deep within the periplasm. The resulting complex is stabilised by complementary electrostatic interactions and hydrogen bonds and spans much of the periplasmic helical region of TolC as well as its transmembrane $\beta$ barrel domain.

$\mathrm{KlebC}_{1-254}$ projects beyond the iris of $\mathrm{KqTolC}$. In the KqTolC$\mathrm{KlebC}_{1-254}$ complex, the density for helix 1 of KlebC coincides with the tapering of the TolC channel into the iris (Fig. 2c). This suggests that in order for $\mathrm{KlebC}_{1-254}$ to adopt its TolC-bound conformation the N-terminal end of helix 1 has to unfold. Helical unfolding would be consistent with the entropically driven binding observed by ITC (Fig. 1b). Two possibilities might account for the absence of $\mathrm{N}$-terminal residues of KlebC from the structure of the complex; either they reside unstructured within the lumen of TolC or they protrude beyond the iris of TolC, which would require local structural perturbations, not resolved in the current structure, to allow an unstructured polypeptide to fit through. We can discount the possibility that these sequences pass between the periplasmic helices of the TolC channel since the positions of the helices are essentially identical in the KlebCbound and unliganded forms of KqTolC (Supplementary Fig. 7).

Protease protection assays using trypsin were performed to ascertain how much of the $\mathrm{KlebC}_{1-254}$ sequence was solvent accessible in the KqTolC-KlebC ${ }_{1-254}$ complex. KqTolC alone was largely resistant to trypsin, with denaturing mass spectrometry (MS) showing only 13 residues in addition to the His tag cleaved from its C-terminus, whilst $\mathrm{KlebC}_{1-254}$ was completely degraded within $5 \mathrm{~min}$ by trypsin (Supplementary Fig. 8). Following 120 min of trypsin digestion, the $\mathrm{KqTolC}-\mathrm{KlebC}_{1-254}$ complex was purified by gel-filtration chromatography and the eluate analysed by both native-state MS and peptide mass fingerprinting of bound (protected) KlebC (Fig. 3). The main species identified by nativestate MS was the TolC trimer, truncated at its C-terminus, in complex with a peptide of $10,598 \mathrm{Da}$, which corresponds to $\mathrm{Kleb}_{67-163}$. However, there was considerable heterogeneity in the KlebC peptide fragments identified; starting at residue 63/67/81 and ending at 155/157/163/164/165/168/172, hence results from native-state MS were validated by proteomics. SDS-PAGE analysis of the purified trypsin-digested $\mathrm{KqTolC}-\mathrm{KlebC}_{1-254}$
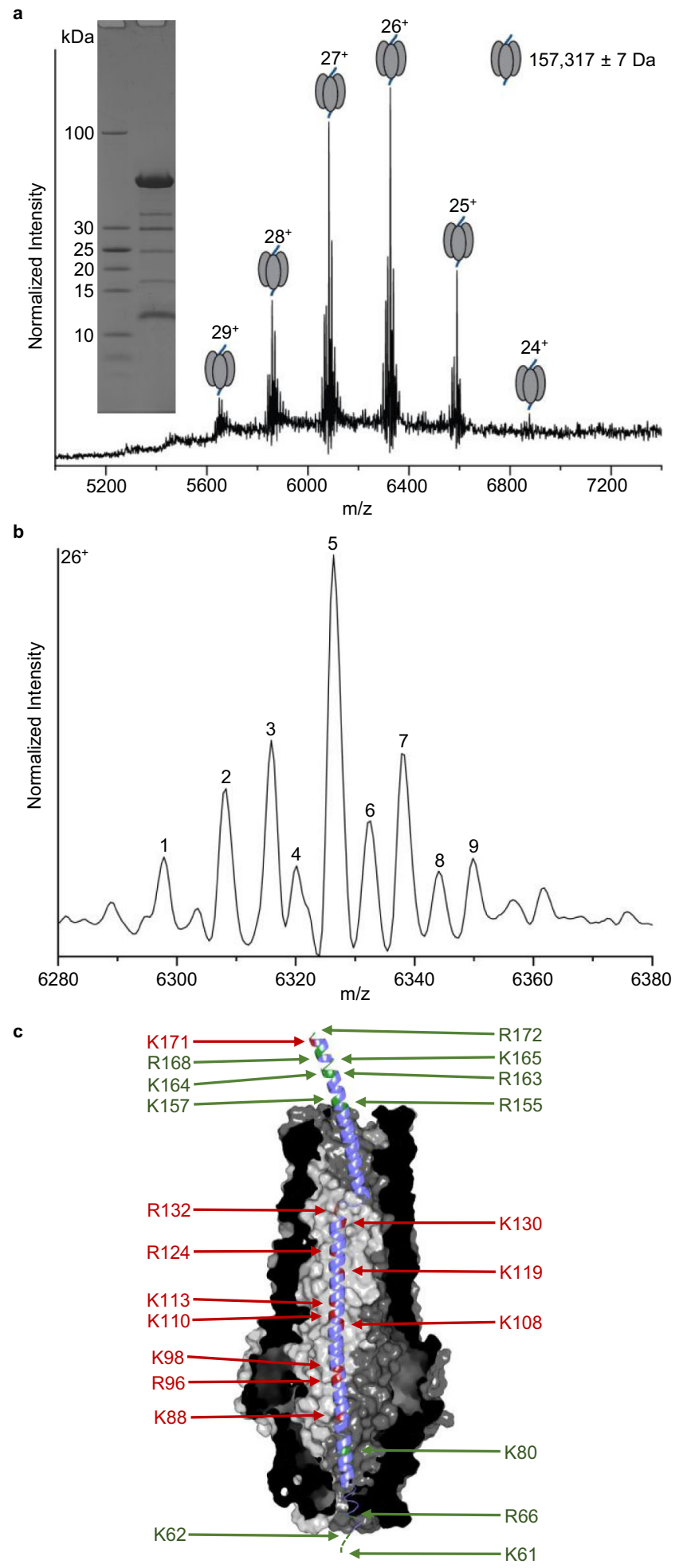

complex (Fig. 3a, inset) showed five prominent bands in addition to TolC. Further in-gel trypsin digestion of these bands combined with LC-MS showed peptides $>15 \mathrm{kDa}$ were derived from TolC while those $\sim 10 \mathrm{kDa}$ belonged to KlebC. Within the $10-\mathrm{kDa}$ KlebC fragment, three peptides, spanning $\mathrm{KlebC}_{67-80}, \mathrm{KlebC}_{81-88}$ and $\mathrm{KlebC}_{114-124}$, were dominant along with several lower abundance peptides (Supplementary Table 4). Combined, these data demonstrate that $\sim 13$ cleavage sites within $\mathrm{KlebC}_{1-254}$ are protected from trypsin when bound to TolC. These sites span 
Fig. 3 Mapping the regions of KlebC1-254 protected from trypsin by

KqTolC. a Native-state ESI-MS spectrum of the trypsin-digested KqTolC$\mathrm{KlebC}_{1-254}$ complex. Representative spectra shown from $n=3$ technical replicates. Inset, 10-20\% SDS-PAGE analysis of trypsin-digested KqTolC$\mathrm{KlebC}_{1-254}$ complex after purification by gel-filtration chromatography. $\mathbf{b}$ Detailed view of the $26^{+}$charge state showing heterogeneity of the sample. Numbered peaks are assigned in Supplementary Table 3. c Cartoon representation of $\mathrm{KlebC}_{67-163}$ bound within the lumen of $\mathrm{KqTolC}$. The figure was constructed by superposing residues 63-81 and residues 145-172 of the $\mathrm{KlebC}_{51-254}$ crystal structure onto the $\mathrm{KlebC}_{77-151}$ seen within the TolC lumen of the cryo-EM structure. Cleaved trypsin sites are highlighted in green whilst uncut sites are shown in red.

residues 67-163, confirming the identity of the proteolysed complex observed by native-state MS (Fig. 3). Of these, residues 77-151 are resolved in the cryo-EM structure of the complex. Heterogeneity in the sites of KlebC cleavage likely reflects dynamics within the complex, with observed cleavage at K80 requiring deviation from the state observed in the cryo-EM structure. We conclude that the majority of the $\mathrm{KlebC}_{1-254} \mathrm{C}$ terminus ( 100 residues) is exposed in the complex with TolC, consistent with much of helix 2 projecting out of the tunnel. Importantly, two $\mathrm{N}$-terminal trypsin sites, at positions 61 and 62, are not protected (there are no other trypsin sites in the first 60 residues of the construct). Hence, concomitant with the formation of the $\mathrm{KqTolC}-\mathrm{KlebC}_{1-254}$ complex, the N-terminal $\sim 60$ residues of $\mathrm{KlebC}_{1-254}$, which houses the bacteriocin's TonBbox motif, likely escapes through the TolC iris to become solventexposed. The consequences of this binding mode are explored further in "Discussion".

KlebC inhibits drug efflux through TolC. We hypothesised that the high-affinity binding of $\mathrm{KlebC}_{1-254}$ to the $\mathrm{KqTolC}$ lumen might impact its function as a drug efflux channel. To address this possibility, $\mathrm{KlebC}_{1-254}$ was added to $K$. quasipneumoniae Qmp M1-977 cells, and the ability of these cells to efflux Nile Red was monitored using fluorescence (Fig. 4). Nile Red efflux is a standard assay in studies investigating TolC-mediated export in live bacterial cells $s^{27}$. We found that $1 \mu \mathrm{M} \mathrm{KlebC}_{1-254}$ was sufficient to show significant inhibition of Nile Red efflux, with concentrations from 10 to $100 \mu \mathrm{M} \quad \mathrm{KlebC}_{1-254}$ reaching the maximum inhibition observed. Whilst $\mathrm{KlebC}_{1-254}$ bound TolC with an affinity tenfold higher than $\mathrm{KlebC}_{51-254}$, the former contains an intact TonB-binding sequence within its unstructured $\mathrm{N}$-terminus meaning that this inhibitor can be transported across the outer membrane in a TonB-dependent manner. In total, $1 \mu \mathrm{M}$ $\mathrm{KlebC}_{51-254}$ inhibited Nile Red efflux, but to a lesser extent than was seen with the higher affinity inhibitor $\mathrm{KlebC}_{1-254}$. However, at $10 \mu \mathrm{M}$, inhibition afforded by $\mathrm{KlebC}_{51-254}$ exceeded that of $\mathrm{KlebC}_{1-254}$ and at $100 \mu \mathrm{M} \mathrm{KlebC}_{51-254}$ gave near-complete inhibition of Nile Red efflux.

TolC plays a critical role in the excretion of compounds that would otherwise be toxic to the cell ${ }^{3}$. E. coli tolC deletion strains have been shown to have increased sensitivity to numerous compounds including Rhodamine 6G, where the MIC changes from $1.28 \mathrm{mg} \mathrm{ml}^{-1}$ in wild-type strains to $2.5 \mu \mathrm{g} \mathrm{ml}^{-1}$ in a tolC deletion ${ }^{28}$. The impact of TolC inhibition by KlebC was assessed by preparing tenfold serial dilutions of $K$. quasipneumoniae cultures in the presence of 0,1 or $10 \mu \mathrm{M} \mathrm{KlebC}_{1-254}$ or $\mathrm{KlebC}_{51-254}$ followed by growth on LB-Agar supplemented with $1 \mathrm{mg} \mathrm{ml}^{-1}$ Rhodamine 6G. The addition of KlebC-based inhibitors impacted the ability of $K$. quasipneumoniae to grow in the presence of Rhodamine $6 \mathrm{G}$, with $\mathrm{KlebC}_{51-254}$ giving the most prominent inhibition, preventing growth after dilution in $10 \mu \mathrm{M}$ inhibitor, a
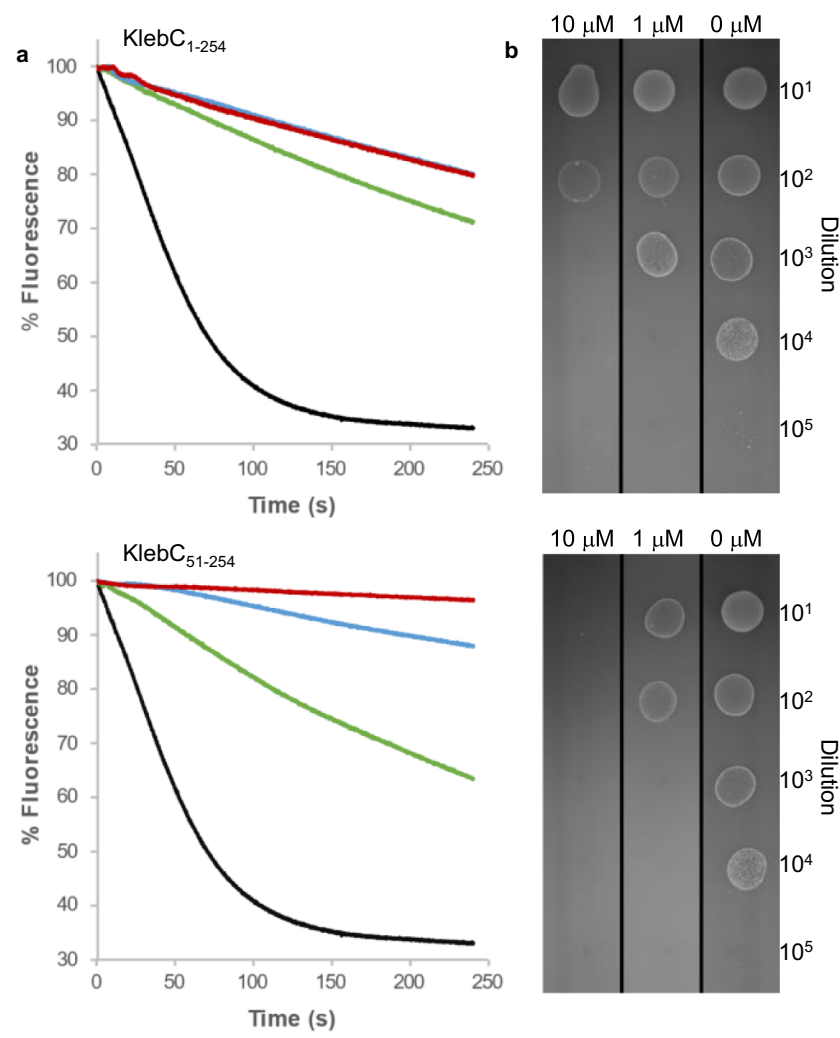

Fig. 4 KlebC fragment-based inhibition of TolC efflux activity resulting in decreased viability of $\boldsymbol{K}$. quasipneumoniae. a Inhibition of Nile Red Efflux through TolC in the presence of $100 \mu \mathrm{M}$ (red), $10 \mu \mathrm{M}$ (blue), $1 \mu \mathrm{M}$ (green) or $0 \mu \mathrm{M}$ (black) $\mathrm{KlebC}_{1-254}$ or $\mathrm{KlebC}_{51-254}$. Data shown are one representative experiment of two biological repeats. $\mathbf{b}$ Growth of serial dilution of $K$. quasipneumoniae prepared in the presence of 10,1 or $0 \mu \mathrm{M}$ $\mathrm{KlebC}_{1-254}$ or $\mathrm{KlebC}_{51-254}$ when plated onto LB-Agar in the presence of $1 \mathrm{mg}$ $\mathrm{ml}^{-1}$ Rhodamine $6 \mathrm{G}$.

4-log reduction compared to growth in its absence. We conclude that TolC-mediated drug efflux is inhibited by the N-terminal helical-hairpin domain of KlebC and that the efficacy of this inhibition is enhanced when bacteriocin translocation into cells is abolished through the removal of the TonB box.

\section{Discussion}

In this study, we used a KlebC-E9 DNase hybrid protein to define the outer-membrane uptake pathway of the bacteriocin KlebC in Klebsiella spp. We demonstrated that an N-terminal 254-residue domain binds TolC with high affinity and likely uses the efflux channel both as its OM receptor and translocator since no additional outer-membrane proteins are required. TolC dependence for bacteriocin toxicity has been shown previously for $E$. coli-specific bacteriocins, ColE1, Col5 and Col10. In these instances, however, toxicity is also dependent on additional OM proteins acting as the receptor for the toxin; BtuB in the case of ColE1, Tsx for Col5 and Col10 $0^{5}$. All these toxins have a TolCbinding domain at the N-terminus similar to that of KlebC (Supplementary Fig. 1e), which we show by crystallography forms a helical-hairpin spanning $150 \AA$ and where the first $\sim 60$ residues are disordered. Disordered N-termini are a common structural feature of bacteriocins, particularly those produced by the Enterobacteriaceae. This region contains epitopes destined to contact energised TonB or Tol proteins in the periplasm, as in the case of KlebC which houses a TonB box. In order to deliver these epitopes to the periplasm, however, an outer-membrane 


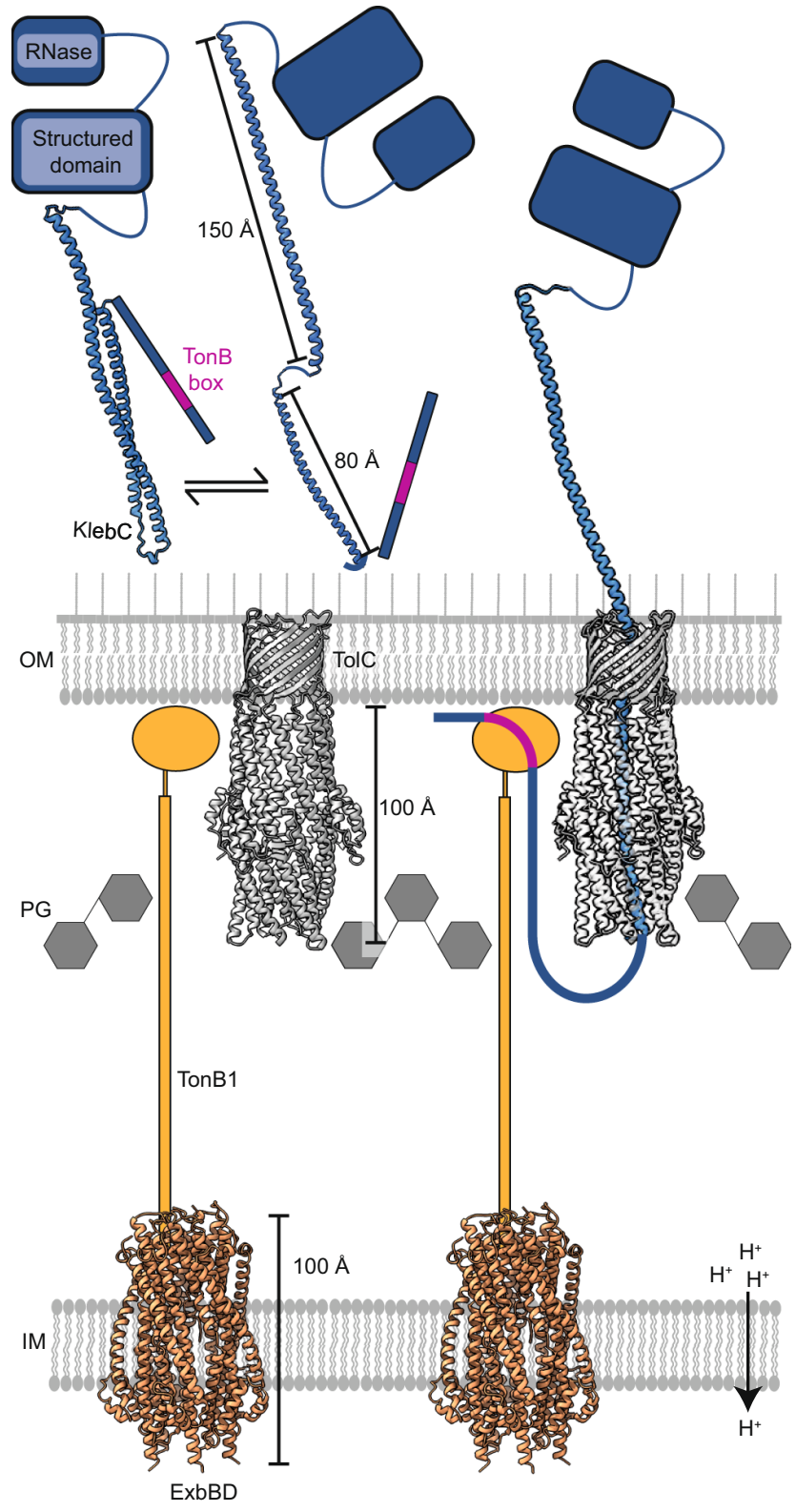

Fig. 5 Model depicting how the KlebC toxin crosses the OM through

TolC. The N-terminal domain of KlebC (blue) exists as a folded hairpin in solution, with a disordered $\mathrm{N}$-terminal domain containing a TonB-box sequence (magenta). The helical hairpin is likely in equilibrium with an unfurled counterpart, which is the binding-competent form of KlebC. We speculate that electrostatic attraction brings the positively charged $\mathrm{N}$ terminus of KlebC into the negatively charged TolC channel. Thereafter, $\mathrm{KlebC}$ snakes through the TolC channel, resulting in ultra-slow association kinetics for the complex. The disordered $\mathrm{N}$-terminal region of $\mathrm{KlebC}$ then passes through the periplasmic entrance of TolC, which likely requires flexing of the iris helices to accommodate a disordered polypeptide. Around 70 residues at the $\mathrm{N}$-terminus of $\mathrm{KlebC}$ escape the iris leaving the helical regions of KlebC docked within the TolC channel. The disordered nature of these residues means that a wide search radius is possible. Toxin translocation is driven by TonB, which associates with the KlebC TonB box (residues 16-20), in conjunction with the PMF-linked inner membrane stator complex ExbB-ExbD. Previous work on TonB-dependent bacteriocins has shown that this protein-protein interaction is sufficient to drive entry into the cell13. How the nuclease then translocates to the cytoplasm is not known but may involve the inner membrane AAA+ATPase/protease $\mathrm{FtsH}$, as has been shown for E. coli-specific colicins ${ }^{52,53}$. translocator is required, with delivery being either active or passive. Examples of energised transfer include pyocins S2 and S5 in $P$. aeruginosa, where both toxins exploit the PMF to deliver a TonB box through their OM TBDT translocator prior to import $^{13,29}$. Passive transfer of bacteriocin disorder epitopes includes those of colicins E2-E9 in E. coli, whereby contact with TolB in the periplasm is achieved by insertion of the disordered sequence at the $\mathrm{N}$-termini of these toxins through the pores of the general porins $\mathrm{OmpF}$ or $\mathrm{OmpC}^{16,30}$. Our protease protection assays suggest that KlebC similarly manages to passively translocate its disordered N-terminal domain, containing the TonB box, through the iris of TolC into the periplasm.

KlebC uses a highly unusual binding mechanism to associate with its outer-membrane receptor/translocator TolC, in which its $\mathrm{N}$-terminal helical-hairpin domain opens like a switchblade knife. Remarkably, this unfurling is not rate-limiting for binding to the TolC channel, as suggested by our stopped-flow experiments. We speculate that the ultra-slow on-rate for the complex instead reflects the $\mathrm{N}$-terminal disordered region and helix 1 snaking through the channel following hairpin unfurling. Once bound, KlebC then likely extends its remaining domains from the cell surface (Fig. 5).

TolC constitutes the exit channel for different tripartite efflux pumps that span the two membranes of the Gram-negative cell envelope, coupling expulsion of antibiotics and toxins to either proton flow across the inner membrane or ATP hydrolysis in the cytoplasm $^{31}$. Examples include AcrAB, EmrAB and MacAB. In each case, one protein acts as the adapter (e.g. AcrA) linking the energised protein (e.g. AcrB) in the inner membrane to the periplasmic entrance of TolC. Indeed, TolC is recruited to efflux pumps loaded with secretable substrates by their adapters (reviewed by Koronakis et al. ${ }^{3}$ ). The present work emphasises that the TolC channel can be recruited to energised inner membrane systems not involved in drug or toxin efflux. By coupling to the PMF-linked TonB/ExbBD complex, TolC acts as an OM translocation portal for bacteriocins that present a TonB-box epitope to the periplasm. TolC can also be recruited to the PMF-linked TolA/TolQR complex in the inner membrane since some group A bacteriocins, such as ColE1, present Tol protein interaction epitopes in the periplasm via TolC ${ }^{5}$. Finally, since the high-affinity binding of KlebC to TolC blocks drug efflux, we suggest these proteins may be the starting point for developing approaches to counter multidrug-resistant Gram-negative bacteria.

\section{Methods}

Molecular biology. A synthetic gene encoding heterodimeric NdeI-KlebC/ImCXhoI codon optimised for E. coli expression (Eurofins genomics) could not be assembled from its three component parts due to its toxicity. Following truncation of KlebC to replace the cytotoxic domain with a NcoI site, NdeI-KlebC $\Delta$ rRNase$\mathrm{NcoI}$ was constructed and cloned into the $\mathrm{NdeI} / \mathrm{NcoI}$ sites of $\mathrm{pCS} 4^{32}$ to give $\mathrm{KlebC}$ E9 DNase/Im9 $9_{\text {His }}$ in pET21a. N- and C-terminal truncations and site-directed mutagenesis were performed through standard PCR techniques and cloned into the NdeI/XhoI sites of pET21a or pET24a. TolC was amplified from Klebsiella quasipneumoniae Qmp M1-977 genomic DNA and cloned into the NdeI/Xhol sites of pET24a such that the plasmid provided a C-terminal $\mathrm{His}_{6}$ tag on TolC. A complete list of plasmids used in this work is given in Supplementary Table 5, and the primers used in their construction and mutagenesis are given in Supplementary Table 6.

Protein expression and purification. TolC was expressed in T7 Express lysY/Iq cells (NEB) transformed with pNGH317 and grown in LB (Lennox) supplemented with $50 \mu \mathrm{g} \mathrm{ml}^{-1}$ kanamycin at $37^{\circ} \mathrm{C}$ to an $\mathrm{OD}_{600}$ of 0.75 upon which IPTG was added to a final concentration $1 \mathrm{mM}$, followed by a further $4 \mathrm{~h}$ growth at $20^{\circ} \mathrm{C}$. Cells were harvested by centrifugation $\left(5000 \times g, 12 \mathrm{~min}, 4^{\circ} \mathrm{C}\right)$ and cell pellets resuspended in $10 \mathrm{mM}$ Tris- $\mathrm{HCl}$, $\mathrm{pH}$ 8.0, 0.25\% (w/v) lithium, 3,5-diiodosalicylic acid in the presence of $1 \mathrm{mM}$ PMSF. Cells were lysed through sonication (Misonix S-4000) and insoluble cell debris removed by centrifugation $\left(5000 \times g, 15 \mathrm{~min}, 4^{\circ}\right.$ C), before pelleting membranes from the supernatant $\left(200,000 \times g, 1 \mathrm{~h}, 4^{\circ} \mathrm{C}\right)$. Outer-membrane proteins were detergent solubilised in $10 \mathrm{mM}$ Tris- $\mathrm{HCl}, \mathrm{pH} 8.0$, $5 \mathrm{mM}$ EDTA and $2 \%(\mathrm{w} / \mathrm{v}) \beta-\mathrm{OG}$, with insoluble material removed by 
ultracentrifugation $\left(200,000 \times g, 1 \mathrm{~h}, 4^{\circ} \mathrm{C}\right)$. EDTA was removed from the supernatant using a HiPrep 26/10 desalting column (Cytiva) equilibrated in $25 \mathrm{mM}$ Tris$\mathrm{HCl}, \mathrm{pH} 7.5,150 \mathrm{mM} \mathrm{NaCl}, 1 \%$ (w/v) $\beta$-OG. Protein was purified on a $5-\mathrm{ml}$ HisTrap FF column (Cytiva) equilibrated in $25 \mathrm{mM}$ Tris-HCl, pH 7.5, $150 \mathrm{mM}$ $\mathrm{NaCl}, 1 \%(\mathrm{w} / \mathrm{v}) \beta-\mathrm{OG}$, eluting bound material with a $0-500 \mathrm{mM}$ imidazole gradient. Homogeneous TolC was obtained after passing the nickel column eluate down a HiLoad 16/600 Superdex 200 pg column (Cytiva) equilibrated in $25 \mathrm{mM}$ Tris- $\mathrm{HCl}, \mathrm{pH} 7.5,150 \mathrm{mM} \mathrm{NaCl}, 1 \%$ (w/v) $\beta$-OG.

KlebC-E9/Im9, truncated KlebC constructs and mutants were expressed in BL21 (DE3) transformed with the appropriate plasmids and grown at $37^{\circ} \mathrm{C}$ in $\mathrm{LB}$ (Miller) supplemented with either $50 \mu \mathrm{g} \mathrm{ml}^{-1}$ kanamycin or $100 \mu \mathrm{g} \mathrm{ml}^{-1}$ ampicillin. Cultures were grown to an $\mathrm{OD}_{600}$ of 0.75 upon which expression was induced by the addition of IPTG to a final concentration of $1 \mathrm{mM}$, followed by a further 4 hours growth at $28^{\circ} \mathrm{C}$ before harvesting by centrifugation $(5000 \times g, 12$ $\min , 4^{\circ} \mathrm{C}$ ). Cell pellets were resuspended in $20 \mathrm{mM}$ Tris- $\mathrm{HCl}, \mathrm{pH} 8.0,500 \mathrm{mM}$ $\mathrm{NaCl}, 8 \mathrm{mM}$ imidazole $1 \mathrm{mM}$ PMSF, lysed by sonication and clarified by centrifugation at $17,500 \times g$ for $30 \mathrm{~min}$ at $4{ }^{\circ} \mathrm{C}$, before passing through a $0.45-\mu \mathrm{m}$ filter and loading onto a $5 \mathrm{ml}$ HisTrap FF column (Cytiva). Bound material was eluted with an imidazole gradient to $500 \mathrm{mM}$. Fractions containing the protein of interest were pooled and buffer exchanged into $25 \mathrm{mM}$ Tris- $\mathrm{HCl}, \mathrm{pH} 7.5,150 \mathrm{mM}$ $\mathrm{NaCl}$, by overnight dialysis prior to further purification on a HiLoad 26/600 Superdex 200 pg column (Cytiva) for KlebC-E9/Im9 or a HiLoad 26/600 Superdex $75 \mathrm{pg}$ column (Cytiva) for truncated KlebC constructs, equilibrated in the same buffer. Proteins were quantified through the measurement of $\mathrm{A}_{280}$ using sequencebased extinction coefficients.

For the preparation of selenomethionine-labelled $\mathrm{KlebC}_{51-254}$, T7 Express Crystal competent $E$. coli (NEB) transformed with pNGH337 were used to inoculate $50 \mathrm{ml}$ cultures of $\mathrm{M} 9$ media supplemented with $2 \mathrm{mM} \mathrm{MgSO}_{4}, 0.1 \mathrm{mM}$ $\mathrm{CaCl}_{2}, 0.4 \%$ (w/v) glucose, $0.0002 \%(\mathrm{w} / \mathrm{v})$ ferric ammonium acetate, $50 \mu \mathrm{g} \mathrm{ml}^{-1} \mathrm{~L}-$ methionine and $50 \mu \mathrm{g} \mathrm{ml}^{-1}$ kanamycin, which were then grown for $20 \mathrm{~h}$ at $37^{\circ} \mathrm{C}$. In all, $25 \mathrm{ml}$ of this culture was used to inoculate $660 \mathrm{ml}$ of the same media, which was grown at $37^{\circ} \mathrm{C}$ to an $\mathrm{OD}_{600}$ of 0.7 before harvesting by centrifugation at $4000 \times$ $g$ for $15 \mathrm{~min}$ at $20^{\circ} \mathrm{C}$. Cell pellets were resuspended in $660 \mathrm{ml} \mathrm{M9} \mathrm{media}$

supplemented with $2 \mathrm{mM} \mathrm{MgSO}_{4}, 0.1 \mathrm{mM} \mathrm{CaCl}_{2}, 0.4 \%$ (w/v) glucose, $0.0002 \%(\mathrm{w} /$ v) ferric ammonium acetate and $50 \mu \mathrm{g} \mathrm{ml}^{-1}$ kanamycin and were grown at $37^{\circ} \mathrm{C}$ for $2.5 \mathrm{~h}$ to deplete methionine. Selenomethionine was added $(50 \mu \mathrm{g} \mathrm{ml}-1)$,

followed by $30 \mathrm{~min}$ growth at $37^{\circ} \mathrm{C}$ before inducing expression with $1 \mathrm{mM}$ IPTG. Cells were grown for a further $3 \mathrm{~h}$ at $37^{\circ} \mathrm{C}$ before harvesting by centrifugation, with the remainder of the purification performed, as described above.

For the preparation of NMR samples, BL21 (DE3) cultures transformed with appropriate plasmids were grown in M9 media supplemented with $2 \mathrm{mM} \mathrm{MgSO}_{4}$, $0.1 \mathrm{mM} \mathrm{CaCl} 2,0.4 \%(\mathrm{w} / \mathrm{v})$ glucose, $0.17 \%(\mathrm{w} / \mathrm{v})$ yeast nitrogen base, $15 \mathrm{mM}$ ${ }^{15} \mathrm{NH}_{4} \mathrm{Cl}$ in the presence of $50 \mu \mathrm{g} \mathrm{ml}^{-1}$ kanamycin at $37^{\circ} \mathrm{C}$ to an $\mathrm{OD}_{600}$ of 0.5 , upon which IPTG was added to $1 \mathrm{mM}$ and cultures were grown for a further $3 \mathrm{~h}$ at $37^{\circ} \mathrm{C}$. The remainder of the purification was performed as described above.

KlebC cytotoxicity assay. Killing assays were performed using Klebsiella quasipneumoniae Qmp M1-977, in addition to BW25113, JW0940 (BW25113 ompA-), JW5503 (BW25113 tolC-), JW0452 (BW25113 acrA-), JW0451 (BW25113 acrB-), JW0729 (BW25113 tolA-) and JW5195 (BW25113 tonB-) from the Keio collection obtained through The Coli Genetic Stock Center, Yale. In total, $5 \mathrm{ml}$ molten LB$0.7 \%(\mathrm{w} / \mathrm{v})$ Agar inoculated with mid-log culture was overlaid onto $20 \mathrm{ml} \mathrm{LB}-$ $1.5 \%(\mathrm{w} / \mathrm{v})$ Agar in a 90-mm Petri dish and allowed to set. In all, $5 \mu \mathrm{l}$ of 27, 9, 3, 1 and $0.3 \mu \mathrm{M} \mathrm{KlebC}$ were spotted onto the plate and once dry were incubated at $37^{\circ}$ $\mathrm{C}$ overnight. KlebC activity resulted in zones of clearance in the bacterial lawn.

In vivo assembly and extraction of KlebC complexes. Two $50 \mathrm{ml}$ of nutrient broth (Merck) cultures of K. quasipneumoniae Qmp M1-977 grown for $8 \mathrm{~h}$ at $37^{\circ} \mathrm{C}$ were each used to inoculate $1 \mathrm{~L}$ of nutrient broth, which was then grown for a further $16 \mathrm{~h}$ at $37^{\circ} \mathrm{C}$. Cell pellets were harvested by centrifugation at $5000 \times g$ at $4{ }^{\circ}$ $\mathrm{C}$ for $12 \mathrm{~min}$. Pellets were resuspended in $10 \mathrm{mM}$ Tris-HCl, $\mathrm{pH} 8.0,0.25 \%(\mathrm{w} / \mathrm{v})$ lithium, 3,5-diiodosalicylic acid, $1 \mathrm{mM}$ PMSF with and without $10 \mathrm{mg}$ KlebC-E9/ $\operatorname{Im} 9_{\text {His6. }}$. Samples were lysed through sonication followed by centrifugation at $15,000 \times g$ for $15 \mathrm{~min}$ at $4^{\circ} \mathrm{C}$ to remove cell debris. Total membranes were pelleted through centrifugation at $200,000 \times g$ for $1 \mathrm{~h}$ at $4{ }^{\circ} \mathrm{C}$. Inner membranes were extracted in $10 \mathrm{mM}$ Tris- $\mathrm{HCl}, \mathrm{pH} 8.0,0.25 \%(\mathrm{w} / \mathrm{v})$ lithium, 3,5-diiodosalicylic acid, $2 \%(\mathrm{v} / \mathrm{v})$ Triton X-100 with outer membranes again pelleted at $200,000 \times g$ for $1 \mathrm{~h}$ at $4{ }^{\circ} \mathrm{C}$. Outer-membrane pellets were washed with $25 \mathrm{ml}$ of $10 \mathrm{mM}$ Tris- $\mathrm{HCl}, \mathrm{pH}$ 8.0 to remove excess Triton X-100, followed by centrifugation at $200,000 \times g$. Outer membranes were solubilised in $10 \mathrm{mM}$ Tris- $\mathrm{HCl}, \mathrm{pH} 8.0,5 \mathrm{mM}$ EDTA, $2 \%(\mathrm{w} / \mathrm{v})$ $\beta$-OG, followed by centrifugation at $200,000 \times g$. The outer-membrane extracts were buffer exchanged into $10 \mathrm{mM}$ Tris- $\mathrm{HCl}, \mathrm{pH} 8.0,1 \%(\mathrm{w} / \mathrm{v}) \beta-\mathrm{OG}$ using a HiPrep 26/10 desalting column (Cytiva) before loading onto a 1-ml HisTrap HP column (Cytiva) and eluting bound material with a $0-500 \mathrm{mM}$ imidazole gradient over 10 column volumes. Eluted fractions for both the control and KlebC-E9 DNase/Im $9_{\text {His } 6}$ baited sample, were analysed on a $10 \%$ SDS-PAGE gel. Protein bands unique to the sample in the presence of bait protein were subjected to in-gel digest with trypsin followed by peptide fingerprinting.
Analytical gel-filtration chromatography. KlebC constructs and TolC were buffer exchanged into $25 \mathrm{mM}$ Tris- $\mathrm{HCl}, \mathrm{pH} 7.5,150 \mathrm{mM} \mathrm{NaCl}, 1 \%$ (w/v) $\beta-\mathrm{OG}$ using a $5 \mathrm{ml}$ HiTrap desalting column (Cytiva) before preparing individual components at a concentration of $5 \mu \mathrm{M}$ and complexes containing $5 \mu \mathrm{M}$ of each component. In all, $500 \mu \mathrm{l}$ of each sample was injected onto a 10/300 Superdex 200 GL column (Cytiva) equilibrated in the same buffer. Analytical gel filtration was performed at a flow of $0.5 \mathrm{ml} / \mathrm{min}$ monitoring eluate at $280 \mathrm{~nm}$ and $220 \mathrm{~nm}$. The impact of disulphide bonds on complex formation was investigated by treating KlebC-E9 DNase/Im9 with either $5 \mathrm{mM}$ diamide or $5 \mathrm{mM}$ DTT prior to gel filtration. The gel filtration itself was performed in $25 \mathrm{mM}$ Tris- $\mathrm{HCl}, \mathrm{pH} 7.5,150 \mathrm{mM}$ $\mathrm{NaCl}, 1 \%(\mathrm{w} / \mathrm{v}) \beta$-OG in the absence of oxidising or reducing agents.

Equilibrium fluorescence measurements. Equilibrium fluorescence measurements were made on a Horiba FluoroMax- 4 spectrofluorimeter at $25^{\circ} \mathrm{C}$. Fluorescence spectra were measured in a $5 \mathrm{~mm}$ cuvette using excitation wavelengths of 280 or $295 \mathrm{~nm}$ collecting emissions over $300-400 \mathrm{~nm}$ for tryptophan emissions or $400-550 \mathrm{~nm}$ for AEDANS fluorescence, with excitation and emission slit widths of $2 \mathrm{~nm}$.

Pre-equilibrium fluorescence. Pre-equilibrium fluorescence measurements were performed on an SX20 stopped-flow (Applied Photophysics), using 1:1 vol:vol mixing ratio, at $25^{\circ} \mathrm{C}$. Excitation wavelengths of 280 or $295 \mathrm{~nm}$ were selected with a monochromator, with slit widths of $0.5 \mathrm{~mm}$ and emission wavelengths above 320 $\mathrm{nm}$ (for tryptophan fluorescence) or $445 \mathrm{~nm}$ (for AEDANS fluorescence) were selected with cut-off filters. Data were collected over suitable time courses (varying from $50 \mathrm{~ms}$ to $1000 \mathrm{~s}$ ) under pseudo-first-order conditions. The apparent rate constant was obtained by fitting data to a single exponential equation, with $k_{\text {o }}$ determined from the gradient of $k_{\text {app }}$ plotted against a range of excess protein concentrations.

Isothermal titration calorimetry. Titrations were performed on an iTC200 isothermal titration calorimeter (Malvern instruments), with proteins buffer exchanged into $25 \mathrm{mM}$ Tris- $\mathrm{HCl}, \mathrm{pH} 7.5,1 \%$ (w/v) $\beta$-OG using a $5 \mathrm{ml}$ HiTrap desalting column (Cytiva). KlebC constructs were used in the syringe at concentrations between 76 and $89 \mu \mathrm{M}$, whilst TolC trimer was present in the cell at concentrations between 5 and $7.6 \mu \mathrm{M}$. Due to the very slow kinetics of binding, data were collected in no feedback mode, with 750 s spacing between injections. Data were fitted to a single set of identical sites binding model.

Crystallisation. Selenomethionine-labelled $\mathrm{KlebC}_{51-254}$ concentrated to $8.6 \mathrm{mg} \mathrm{ml}^{-1}$ using a VivaSpin20 with $10 \mathrm{kDa}$ MWCO (Sartorius), was used to prepare JCSG +, PACT premier, Morpheus (Molecular Dimensions), PEG/Ion and Index (Hampton Research) commercial screens by sitting-drop vapour diffusion using $100 \mathrm{nl}$ of protein mixed with $100 \mathrm{nl}$ of reservoir solution, at $18^{\circ} \mathrm{C}$. Crystals obtained in 0.2 lithium sulfate, $0.1 \mathrm{M}$ BisTris, pH 5.5, 25\% (w/v) PEG3350 of the Index screen, cryocooled in the presence of $30 \%$ ethylene glycol gave poor-quality powdery diffraction. The remaining crystals from this condition were used to prepare a crystal seed stock using a Microseed Bead (Molecular Dimensions) following the manufacturer's instructions. Commercial screens were again set up using sitting-drop vapour diffusion, this time with $100 \mathrm{nl}$ of $8.6 \mathrm{mg} \mathrm{ml}^{-1}$ selenomethionine-labelled $\mathrm{KlebC}_{51-254}, 50 \mathrm{nl}$ of seed stock and $150 \mathrm{nl}$ of reservoir solution. Crystals were obtained from several conditions with the best diffracting growing in Morpheus condition G1 (0.1 M Morpheus Carboxylic acids, 0.1 M Morpheus Buffer $1 \mathrm{pH}$ 6.5, 30\% v/v Morpheus Precipitant Mix 1). Diffraction data were collected at beamline I04, Diamond Light Source at a wavelength of $0.97932 \AA$ to an upper-resolution limit of $1.9 \AA$. Data reduction was carried out using DIALS $^{33}$ and a substructure of three Se atoms was determined using SHELXD ${ }^{34}$ and refined using PHASER ${ }^{35}$. An initial model was built automatically using BUCANNEER ${ }^{36,37}$ and was completed and refined using iterative cycles of COOT $^{38}$ and BUSTER ${ }^{39}$. Data collection and refinement statistics are presented in Supplementary Table 1 . The atomic coordinates and structure factors for $\mathrm{KlebC}_{51-254}$ have been deposited in the Protein Data Bank (PDB ID code 7NNA).

Liquid growth-killing assay. An overnight culture of K. quasipneumoniae Qmp M1-977 was used to inoculate $100 \mathrm{ml} \mathrm{LB}$ (Miller) which was grown at $37^{\circ} \mathrm{C}$ to an $\mathrm{OD}_{600}$ of $\sim 0.2$ upon which $10 \mathrm{ml}$ aliquots were removed and treated with $100 \mathrm{nM}$ KlebC-E9/Im9, $100 \mathrm{nM}$ A107C, Y177C KlebC-E9/Im9 oxidised with $5 \mathrm{mM}$ diamide, $100 \mathrm{nM}$ A107C, Y177C KlebC-E9/Im9 reduced with $5 \mathrm{mM}$ DTT, $100 \mathrm{nM}$ L86C, L198C KlebC-E9/Im9 oxidised with $5 \mathrm{mM}$ diamide, $100 \mathrm{nM}$ L86C, L198C KlebC-E9/Im9 reduced with $5 \mathrm{mM}$ DTT or no klebicin. Cultures were grown for a further $2 \mathrm{~h}$ monitoring $\mathrm{OD}_{600}$ every $30 \mathrm{~min}$.

Preparation of KlebC-TolC complexes in Amphipol A8-35. $\mathrm{KlebC}_{1-254}$ was added to TolC in a twofold molar excess and the complex was buffer exchanged into $20 \mathrm{mM}$ potassium phosphate, $\mathrm{pH} 7.5,100 \mathrm{mM} \mathrm{NaCl}, 1 \%$ (w/v) $\beta$-OG using a HiPrep $26 / 10$ desalting column (Cytiva). Formaldehyde was added to the complex at a final concentration of $1 \%(\mathrm{w} / \mathrm{v})$ and incubated at room temperature for $30 \mathrm{~min}$ before quenching with $100 \mathrm{mM}$ Tris- $\mathrm{HCl}$. Cross-linked $\mathrm{KlebC}_{1-254}$ :TolC complex was purified on a HiLoad 16/600 Superdex $200 \mathrm{pg}$ column (Cytiva) equilibrated in $20 \mathrm{mM}$ 
potassium phosphate, $\mathrm{pH} 7.5,100 \mathrm{mM} \mathrm{NaCl}, 1 \%$ (w/v) $\beta$-OG. In total, $10 \mathrm{mg}$ of amphipol A8-35 (Anatrace) was added for each $\mathrm{mg}$ of protein and incubated at room temperature for $2 \mathrm{~h}$. In all, $10 \mathrm{mg}$ of BioBeads SM2 (Bio-Rad) were added to the sample per mg of detergent, incubated for $2 \mathrm{~h}$ before centrifuging at $20,000 \times g$ for 5 $\mathrm{min}$ at room temperature. Formaldehyde cross-linked $\mathrm{KlebC}_{1-254}$.TolC complex in amphipol A8-35 was purified on a HiLoad 16/600 Superdex $200 \mathrm{pg}$ column (Cytiva) equilibrated in $20 \mathrm{mM}$ potassium phosphate, $\mathrm{pH} 7.9,100 \mathrm{mM} \mathrm{NaCl}$. Eluate was concentrated to $1.7 \mathrm{mg} \mathrm{ml}^{-1}$ using a VivaSpin Turbo $4,50 \mathrm{kDa}$ (Sartorius) concentrator.

Single-particle Cryo-EM data collection. $\mathrm{KqTolC}-\mathrm{KlebC}_{51-245}$ complex was applied to Quantifoil 300 mesh $\mathrm{Cu}, 1.2 / 1.3$, grids at concentrations of $0.5 \mathrm{mg} \mathrm{ml}^{-1}$ and $0.75 \mathrm{mg} \mathrm{ml}^{-1}$ for native and formaldehyde cross-linked samples, respectively. Samples $(3 \mu \mathrm{l})$ were vitrified using a vitrobot Mark IV (Thermo Fisher) with a blot time of $3 \mathrm{~s}$, blot force of -2 , and wait time of $30 \mathrm{~s}$. Cryo-EM data were acquired on a 300-kV Titan Krios microscope, equipped with a K2 detector (Gatan), recording in counting mode. A pixel size of $0.822 \AA$ was used to collect videos of 30 frames with a dose rate of 4.8 and 3.7 electrons $/ \AA^{2} / \mathrm{s}$, from an 8 -s exposure, resulting in a total dose of 38 and 29 electrons $/ \AA^{2}$ for native and formaldehyde cross-linked samples, respectively. For further collection parameters, see Supplementary Table 2.

Cryo-EM data processing and model building. Initially, motion correction (MotionCorr 2) and CTF estimation (ctffind 4) were carried out using the SIMPLE pipeline ${ }^{40}$. A subset of micrographs (20) was manually picked to generate templates for automatic picking within SIMPLE. Following picking the particle set was cleaned up using $2 \mathrm{D}$ classification, after which Relion-3.0 and Relion-3.1 ${ }^{41-43}$, were used for further processing. Particles (337,277 for the native and 626, 767 for the cross-linked sample) were sorted using 3D classification with three classes. For the uncrosslinked TolC sample, one rubbish class was generated with two other classes appearing similar, thus particles from these classes were combined and processed further with 3D refinement. A final map of TolC without KlebC present extending to $3.4 \AA$, was generated after detergent subtraction, CTF refinement and map sharpening. Processing is summarised in Supplementary Fig. 5.

For the cross-linked TolC-KlebC $\mathrm{C}_{1-254}$ sample, a single 3D class was selected for further processing using $3 \mathrm{D}$ refinement. Following refinement, the resolution of the map extended to $5.5 \AA$ therefore, a second 3D classification step was implemented to sort heterogeneity. Of the three resulting classes, a single class displayed clear additional density present within the TolC $\beta$-barrel, which was attributed to KlebC. Refinement of this class gave a $3.4 \AA$ map, with three short KlebC helices located within the $\beta$-barrel of TolC. The pseudo C3 symmetry apparent in this map led to the re-refinement of the data with C3 symmetry. Subtraction of amphipol shell, CTF refinement and post-processing were subsequently carried out to generate a $2.8 \AA$ TolC-KlebC map. Since biophysical data suggested that only a single KlebC molecule bound the TolC trimer, the particles were expanded using the C3 symmetry and subtracted to give a single TolC monomer. 3D classification of monomeric particles into eight classes without alignment gave three classes that had density consistent with both TolC and KlebC. In these classes, the KlebC density extended past the $\beta$-barrel domain of TolC into the lumen. Reverse subtraction and refinement of the classes a final map from one subclass, with KlebC density that spanned the length of the TolC lumen. After iterative rounds of model building and LocScale ${ }^{44}$ sharpening, the KlebC density within the final map was more clearly resolved.

An atomic model was built for $\mathrm{Kq} \mathrm{TolC}$ after docking of $E$. coli TolC (1EK9) into the native $\mathrm{KqTolC}$ map in chimera ${ }^{45}$ and modification of the sequence within $\operatorname{coot}^{46}$ to match that of $\mathrm{KqTolC}$. Iterative rounds of real-space refinement and manual model building were implemented in phenix ${ }^{47-49}$ and coot, respectively, to yield final models with statistics reported in Supplementary Table 2 and map to model fits Supplementary Fig. 6. To build a model of the KqTolC-KlebC complex, refined $\mathrm{KqTolC}$ was docked into the final $3.1 \AA$ map in chimera. After a round of rigid-body fitting and manual model building in Phenix and Coot, respectively, KlebC was built in de novo, after which the fit was improved through iterative rounds of real-space refinement, manual model building and map sharpening in Phenix, Coot and LocScale, respectively. Due to the weak density corresponding with the KlebC portion of the map, helix 2 was built within coot by modelling two short alanine helices with opposing register. From this dual modelling, the helical register was apparent favouring one conformation and side chains were iteratively mutated, to residues within the KlebC sequence that best fit the unmodelled KlebC density (Supplementary Fig. 6k). Helix 1 was subsequently placed into the remaining density, once again modelled as two polyalanine helices with opposing register. The helix that best fit the density was consistent with that independently assigned to helix 2 . The sequence connecting helix 1 and 2 was built de novo. The final model of KlebC was subsequently cross-validated by alignment to crystal structure model. Final models of $K q \mathrm{TolC}$ and $\mathrm{KqTolC}-\mathrm{KlebC}_{1-254}$ complex uploaded to PDB with access codes 7NG9 and 7NG8, respectively.

Solution NMR of KlebC $\mathbf{C}_{\mathbf{1 - 2 5 4}}$ and $\mathbf{K l e b C}_{\text {51-254. }}$. All NMR experiments were collected at $20^{\circ} \mathrm{C}$ using ${ }^{15} \mathrm{~N}$-labelled $250 \mu \mathrm{M} \mathrm{KlebC} C_{1-254}$ and $250 \mu \mathrm{M} \mathrm{KlebC} \mathrm{C}_{51-254}$ in $95 \% \mathrm{H}_{2} \mathrm{O} / 5 \% \mathrm{D}_{2} \mathrm{O} 25 \mathrm{mM}$ Tris- $\mathrm{HCl}, \mathrm{pH}$ 7.5, $150 \mathrm{mM} \mathrm{NaCl}$. Data were collected using a $750 \mathrm{MHz}$ spectrometer equipped with an Avance III $\mathrm{HD}$ console and a 5 $\mathrm{mm}$ TCI CryoProbe. Resonance assignments for $\mathrm{KlebC}_{1-254}$ and $\mathrm{KlebC}_{51-254}$ were obtained using $2 \mathrm{D}^{1} \mathrm{H}-{ }^{15} \mathrm{~N}$ BEST-TROSY experiments and $3 \mathrm{D}{ }^{15} \mathrm{~N}$-edited NOESYHSQC and ${ }^{15} \mathrm{~N}$-edited TOCSY-HSQC. Backbone dynamics were monitored using the $\left\{{ }^{1} \mathrm{H}\right\}-{ }^{15} \mathrm{~N}$ heteronuclear NOE experiment.

Trypsin digestion of the $\mathrm{KlebC}_{\mathbf{1 - 2 5 4}}$-KqTolC Complex. In total, $20 \mu \mathrm{g}$ of sequencing grade trypsin (Promega) was added to $1 \mathrm{ml}$ of $8 \mu \mathrm{M} \mathrm{KlebC} \mathrm{C}_{1-254}-\mathrm{KqTolC}$ complex in $50 \mathrm{mM}$ ammonium acetate $\mathrm{pH} 7.5,1 \%(\mathrm{w} / \mathrm{v}) \beta$-OG and was incubated for $2 \mathrm{~h}$ at $37^{\circ} \mathrm{C}$, before the addition of $2 \mathrm{mM}$ PMSF and purification on a $10 / 300$ Superdex $200 \mathrm{GL}$ column (Cytiva). The elution peak of $\mathrm{KqTolC}$ in complex with KlebC fragments was analysed on a 10-20\% Tricine SDS-PAGE gel (Invitrogen). The five bands of molecular weights lower than TolC were excised from the gel, digested with trypsin and identified through peptide fingerprinting.

Gel bands were reduced with Tris(2-carboxyehtyl) phosphine (TCEP) and alkylated with chloroacetamide. Following treatment, bands were washed with acetonitrile (100\%) and protein digested overnight with sequencing grade trypsin $(100 \mathrm{ng})$ at $37^{\circ} \mathrm{C}$. Peptides were loaded onto reverse-phase $\mathrm{C} 18$ column and injected onto a Q-Exactive Orbitrap mass spectrometer (Thermofisher Scientific). MaxQuant ${ }^{50}$ was used to search for peptides against an E. coli database, with KqTolC and KlebC sequences annotated within the FASTA. Data were sorted based on the intensity of peptides, with noise being defined as an order of magnitude cut-off from the highest intensity peptide identified within the sample. Within this intensity range only KqTolC and KlebC peptides were sequenced.

\section{Native-state mass spectrometry of trypsin-digested $\mathrm{KlebC}_{1-254}-\mathrm{Kq}_{\mathrm{ToIC}}$ com-} plex. Native-state mass spectrometry was carried out on a Thermo Q-Exactive UHMR Quadrupole-Orbitrap platform. The protein solutions $(1-3 \mu \mathrm{l}, 24 \mu \mathrm{M})$ were loaded into gold-coated borosilicate electrospray ionisation capillary pulled inhouse $^{51}$. An electrospray was generated by elevating the capillary voltage 1.0-1.2 $\mathrm{kV}$ above the instrument orifice $\left(100-150^{\circ} \mathrm{C}\right)$. Typical instrument parameters used resolution of 12,500 (at $\mathrm{m} / \mathrm{z} 200$ ); S-lens $\mathrm{RF} 150 \% ; 200 \mathrm{~ms}$ fixed injection time; 200-250 V HCD energy at a pressure setting of 8.0. Datasets were plotted in OriginPro v. 9.5.1.195 (Northampton, MA). No background subtraction or smoothing was employed.

Nile Red efflux inhibition assay. The inhibition of Nile Red efflux through $\mathrm{Kq}$ TolC by the addition of KlebC fragments was investigated using a method adapted from Bohnert et al. ${ }^{27}$. In total, $10 \mathrm{ml}$ of K. quasipneumoniae Qmp M1-977 overnight culture grown in LB (Miller) were pelleted at $3000 \times g$ for 10 min at room temperature. Cell pellets were resuspended in $20 \mathrm{mM}$ potassium phosphate, $\mathrm{pH} 7.0$, $1 \mathrm{mM} \mathrm{MgCl} 2$, followed by repeat centrifugation. Pellets were resuspended in 20 $\mathrm{mM}$ potassium phosphate, $\mathrm{pH} 7.0,1 \mathrm{mM} \mathrm{MgCl}_{2}$ adjusting the volume to give an $\mathrm{OD}_{600}$ of 1 . Aliquots ( $2 \mathrm{ml}$ ) were transferred into 15 -ml Pyrex centrifuge tubes, and after 15 min carbonyl cyanide 3-chlorophenylhydrazone was added to a final concentration of $100 \mu \mathrm{M}$. After a 15 min incubation at room temperature, inhibitor was added to a concentration of $0,1,10$ or $100 \mu \mathrm{M}$, after a further 15 min Nile Red was added to a final concentration of $5 \mu \mathrm{M}$. Samples were incubated for $3 \mathrm{~h}$ at $37^{\circ} \mathrm{C}$ with shaking, followed by 1 hour at room temperature without shaking. Samples were centrifuged at $3000 \times g$ for $5 \mathrm{~min}$ at room temperature with pellets resuspended in $2 \mathrm{ml}$ of $20 \mathrm{mM}$ potassium phosphate, $\mathrm{pH} 7.0,1 \mathrm{mM} \mathrm{MgCl}_{2}$ supplemented with inhibitor as appropriate.

Nile Red fluorescence was monitored on a Horiba FluoroMax-4 spectrofluorimeter using an excitation wavelength of $552 \mathrm{~nm}$, an emission wavelength of $636 \mathrm{~nm}$, slit widths of $10 \mathrm{~nm}$ at $25^{\circ} \mathrm{C}$. In total, $300 \mu \mathrm{l}$ sample was diluted into $2.7 \mathrm{ml} 20 \mathrm{mM}$ potassium phosphate, $\mathrm{pH} 7.0,1 \mathrm{mM} \mathrm{MgCl}$ and fluorescence emissions monitored for $60 \mathrm{~s}$. Glucose was added to a final concentration of $50 \mathrm{mM}$ and fluorescence emissions recorded for a further $240 \mathrm{~s}$. Fluorescence intensities were normalised such that the intensity immediately after glucose addition was taken a $100 \%$.

Rhodamine 6G toxicity assay. To investigate the impact TolC inhibition has on the ability of K. quasipneumoniae Qmp M1-977 growth in the presence of Rhodamine $6 \mathrm{G}$, tenfold serial dilutions of overnight culture were prepared in 0,1 or 10 $\mu \mathrm{M}$ inhibitor. In all, $5 \mu \mathrm{l}$ of each dilution was spotted onto an LB-Agar plate containing $1 \mathrm{mg} \mathrm{ml}^{-1}$ Rhodamine $6 \mathrm{G}$ and plates were incubated overnight at $37^{\circ} \mathrm{C}$ Plates were imaged on a Syngene G:Box gel documentation system illuminating with Red LEDS in combination with UV-6 cut-off filter.

Reporting summary. Further information on research design is available in the Nature Research Reporting Summary linked to this article.

\section{Data availability}

The data supporting the findings of the study are available in the article and its Supplementary Information. The atomic coordinates and structure factors of $\mathrm{KlebC}_{51-254}$, $\mathrm{KqTolC}$ and the $\mathrm{KqTolC} \cdot \mathrm{KlebC}_{1-254}$ complex have been submitted to the protein structure data bank (PDB ID codes 7NNA, 7NG9 and 7NG8, respectively). Electron 
microscopy density maps have been submitted to the EMDB with accession codes EMD12310 and EMD-12309 for $\mathrm{KqTolC}$ and $\mathrm{KqTolC} \cdot \mathrm{KlebC}_{1-254}$, respectively. Source data are provided with this paper.

Received: 16 March 2021; Accepted: 7 July 2021;

Published online: 30 July 2021

\section{References}

1. Nikaido, H. Molecular basis of bacterial outer membrane permeability revisited. Microbiol. Mol. Biol. Rev. 67, 593-656 (2003)

2. Pagès, J. M., James, C. E. \& Winterhalter, $M$. The porin and the permeating antibiotic: a selective diffusion barrier in Gram-negative bacteria. Nat. Rev. Microbiol. 6, 893-903 (2008).

3. Koronakis, V., Eswaran, J. \& Hughes, C. Structure and function of TolC: the bacterial exit duct for proteins and drugs. Annu. Rev. Biochem. 73, 467-489 (2004).

4. Wandersman, C. \& Delepelaire, P. TolC, an Escherichia coli outer membrane protein required for hemolysin secretion. Proc. Natl Acad. Sci. USA 87, 4776-4780 (1990).

5. Cascales, E. et al. Colicin biology. Microbiol. Mol. Biol. Rev. 71, 158-229 (2007).

6. Granato, E. T., Meiller-Legrand, T. A. \& Foster, K. R. The evolution and ecology of bacterial warfare. Curr. Biol. 29, R521-R537 (2019).

7. Sharp, C., Bray, J., Housden, N. G., Maiden, M. C. J. \& Kleanthous, C. Diversity and distribution of nuclease bacteriocins in bacterial genomes revealed using Hidden Markov Models. PLoS Comput. Biol. 13, e1005652 (2017).

8. Kleanthous, C. Swimming against the tide: progress and challenges in our understanding of colicin translocation. Nat. Rev. Microbiol. 8, 843-848 (2010).

9. Szczepaniak, J., Press, C. \& Kleanthous, C. The multifarious roles of Tol-Pal in Gram-negative bacteria. FEMS Microbiol. Rev. 44, 490-506 (2020).

10. Noinaj, N., Guillier, M., Barnard, T. J. \& Buchanan, S. K. TonB-dependent transporters: regulation, structure, and function. Annu. Rev. Microbiol. 64, 43-60 (2010)

11. Kleanthous, C. et al. Structural and mechanistic basis of immunity toward endonuclease colicins. Nat. Struct. Biol. 6, 243-252 (1999).

12. Vankemmelbeke, M. et al. Energy-dependent immunity protein release during tol-dependent nuclease colicin translocation. J. Biol. Chem. 284, 18932-18941 (2009).

13. White, P. et al. Exploitation of an iron transporter for bacterial protein antibiotic import. Proc. Natl Acad. Sci. USA 114, 12051-12056 (2017).

14. McCaughey, L. C. et al. Discovery, characterization and in vivo activity of pyocin SD2, a protein antibiotic from Pseudomonas aeruginosa. Biochemical J. 473, 2345-2358 (2016).

15. Ng, C. L. et al. Structural basis for $16 \mathrm{~S}$ ribosomal RNA cleavage by the cytotoxic domain of colicin E3. Nat. Struct. Mol. Biol. 17, 1241-1246 (2010).

16. Housden, N. G. et al. Intrinsically disordered protein threads through the bacterial outer-membrane porin OmpF. Science 340, 1570-1574 (2013).

17. Walker, D., Moore, G. R., James, R. \& Kleanthous, C. Thermodynamic consequences of bipartite immunity protein binding to the ribosomal ribonuclease colicin E3. Biochemistry 42, 4161-4171 (2003).

18. Baba, T. et al. Construction of Escherichia coli K-12 in-frame, single-gene knockout mutants: the Keio collection. Mol. Syst. Biol. 2, 2006-0008 (2006).

19. Shi, X. et al. In situ structure and assembly of the multidrug efflux pump AcrAB-TolC. Nat. Commun. 10, 1-6 (2019).

20. Pilsl, H. \& Braun, V. Novel colicin 10: assignment of four domains to TonBand TolC dependent uptake via the Tsx receptor and to pore formation. Mol. Microbiol. 16, 57-67 (1995).

21. Jakes, K. S. The colicin E1 TolC box: identification of a domain required for colicin E1 cytotoxicity and TolC binding. J. Bacteriol. 199, e00412-16 (2017).

22. Zakharov, S. D., Wang, X. S. \& Cramer, W. A. The colicin E1 TolC-binding conformer: pillar or pore function of TolC in colicin import? Biochemistry 55, 5084-5094 (2016).

23. Cramer, W. A., Sharma, O. \& Zakharov, S. D. On mechanisms of colicin import: the outer membrane quandary. Biochemical J. 475, 3903-3915 (2018).

24. Schreiber, G., Haran, G. \& Zhou, H. X. Fundamental aspects of protein-protein association kinetics. Chem. Rev. 109, 839-860 (2009).

25. Dombkowski, A. A. Disulfide by design ${ }^{\text {TM}}$ : a computational method for the rational design of disulfide bonds in proteins. Bioinformatics 19, 1852-1853 (2003).

26. Koronakis, V., Sharff, A., Koronakis, E., Luisi, B. \& Hughes, C. Crystal structure of the bacterial membrane protein TolC central to multidrug efflux and protein export. Nature 405, 914-919 (2000).
27. Bohnert, J. A., Karamian, B. \& Nikaido, H. Optimized Nile red efflux assay of AcrAB-TolC multidrug efflux system shows competition between substrates. Antimicrobial Agents Chemother. 54, 3770-3775 (2010).

28. Sulavik, M. C. et al. Antibiotic susceptibility profiles of Escherichia coli strains lacking multidrug efflux pump genes. Antimicrobial Agents Chemother. 45 , 1126-1136 (2001).

29. Behrens, H. M. et al. Pyocin S5 import into pseudomonas aeruginosa reveals a generic mode of bacteriocin transport. mBio 11, e03230-19 (2020).

30. Lee, S. et al. Transmembrane epitope delivery by passive protein threading through the pores of the OmpF porin trimer. J. Am. Chem. Soc. 142, 12157-12166 (2020).

31. Hinchliffe, P., Symmons, M. F., Hughes, C. \& Koronakis, V. Structure and operation of bacterial tripartite pumps. Annu. Rev. Microbiol. 67, 221-242 (2013).

32. Garinot-Schneider, C., Penfold, C. N., Moore, G. R., Kleanthous, C. \& James, R. Identification of residues in the putative TolA box which are essential for the toxicity of the endonuclease toxin colicin E9. Microbiology 143, 2931-2938 (1997).

33. Beilsten-Edmands, J. et al. Scaling diffraction data in the DIALS software package: algorithms and new approaches for multi-crystal scaling. Acta Crystallogr. Sect. D: Struct. Biol. 76, 385-399 (2020).

34. Schneider, T. R. \& Sheldrick, G. M. Substructure solution with SHELXD. Acta Crystallogr. Sect. D: Biol. Crystallogr. 58, 1772-1779 (2002).

35. McCoy, A. J. et al. Phaser crystallographic software. J. Appl. Crystallogr. 40, 658-674 (2007).

36. Cowtan, K. The Buccaneer software for automated model building. 1. Tracing protein chains. Acta Crystallogr. Sect. D: Biol. Crystallogr. 62, 1002-1011 (2006)

37. Cowtan, K. Completion of autobuilt protein models using a database of protein fragments. Acta Crystallogr. Sect. D: Biol. Crystallogr. 68, 328-335 (2012).

38. Emsley, P., Lohkamp, B., Scott, W. G. \& Cowtan, K. Features and development of Coot. Acta Crystallogr. Sect. D: Biol. Crystallogr. 66, 486-501 (2010).

39. Bricogne, G. et al. BUSTER version 2.10.3. (Global Phasing Ltd., Cambridge, United Kingdom, 2017).

40. Caesar, J. et al. SIMPLE 3.0. Stream single-particle cryo-EM analysis in real time. J. Struct. Biol. X 4, 100040 (2020).

41. Scheres, S. H. W. A bayesian view on cryo-EM structure determination. J. Mol. Biol. 415, 406-418 (2012).

42. Scheres, S. H. W. R. E. L. I. O. N. Implementation of a Bayesian approach to cryo-EM structure determination. J. Struct. Biol. 180, 519-530 (2012).

43. Zivanov, J. et al. New tools for automated high-resolution cryo-EM structure determination in RELION-3. eLife 7, e42166 (2018).

44. Jakobi, A. J., Wilmanns, M. \& Sachse, C. Model-based local density sharpening of cryo-EM maps. eLife 6, e27131 (2017).

45. Pettersen, E. F. et al. UCSF chimera-a visualization system for exploratory research and analysis. J. Computational Chem. 25, 1605-1612 (2004).

46. Emsley, P. \& Cowtan, K. Coot: model-building tools for molecular graphics. Acta Crystallogr. Sect. D: Biol. Crystallogr. 60, 2126-2132 (2004).

47. Liebschner, D. et al. Macromolecular structure determination using X-rays, neutrons and electrons: recent developments in Phenix. Acta Crystallogr. Sect. D: Struct. Biol. 75, 861-877 (2019).

48. Afonine, P. V. et al. Real-space refinement in PHENIX for cryo-EM and crystallography. Acta Crystallogr. Sect. D: Struct. Biol. 74, 531-544 (2018),

49. Afonine, P. V. et al. New tools for the analysis and validation of cryo-EM maps and atomic models. Acta Crystallogr. Sect. D: Struct. Biol. 74, 814-840 (2018).

50. Cox, J. \& Mann, M. MaxQuant enables high peptide identification rates, individualized p.p.b.-range mass accuracies and proteome-wide protein quantification. Nat. Biotechnol. 26, 1367-1372 (2008).

51. Hernández, H. \& Robinson, C. V. Determining the stoichiometry and interactions of macromolecular assemblies from mass spectrometry. Nat. Protoc. 2, 715-726 (2007).

52. Walker, D., Mosbahi, K., Vankemmelbeke, M., James, R. \& Kleanthous, C. The role of electrostatics in colicin nuclease domain translocation into bacterial cells. J. Biol. Chem. 282, 31389-31397 (2007).

53. Pommer, A. J. et al. Mechanism and cleavage specificity of the $\mathrm{H}-\mathrm{N}-\mathrm{H}$ endonuclease colicin E9. J. Mol. Biol. 314, 735-749 (2001).

\section{Acknowledgements}

We thank David Staunton (Molecular Biophysics Suite, Oxford) for help with biophysical analysis of purified proteins, Shabaz Mohammed (Advanced Proteomics Facility, Oxford), Adam Costin (Micron, Central Oxford Structural Imaging Centre (COSMIC)) for support in data collection and Jeremy Keown (Division of Structural Biology, Wellcome Centre for Human Genetics, University of Oxford) for assistance with computational analysis of cryo-EM data and Francesa Short and Derek Pickard (The Wellcome Sanger Institute) for providing Klebsiella quasipneumoniae Qmp M1-977. This 
work was funded by a Wellcome Trust Collaborative Award (201505/Z/16/Z) and by the European Research Council (Advanced grant 742555; OMPorg). Work in the C.V.R. laboratory is supported by a Medical Research Council (MRC) program grant (MR/ N020413/1). T.J.E. is supported by the Royal Society as a Royal Society Newton Inter national Fellow. We also thank the Oxford Biomedical Research Computing (BMRC) facility, a joint development between the Wellcome Centre for Human Genetics and the Big Data Institute (supported by Health Data Research UK and the NIHR Oxford Biomedical Research Centre) for access to computational resources.

\section{Author contributions}

N.G.H., M.W. and C.K. designed research; R.K. provided materials; N.G.H., M.W., E.L., C.R. and T.J.E. performed research; N.G.H., M.W., E.L., C.R., T.J.E., C.V.R. and C.K. analysed the data; N.G.H., M.W. and C.K. wrote the paper.

\section{Competing interests}

The authors declare no competing interests.

\section{Additional information}

Supplementary information The online version contains supplementary material available at https://doi.org/10.1038/s41467-021-24930-y.

Correspondence and requests for materials should be addressed to C.K.

Peer review information Nature Communications thanks Bert van den Berg, Susan Buchanan, and Damian Ekiert for their contribution to the peer review of this work.

Reprints and permission information is available at http://www.nature.com/reprints

Publisher's note Springer Nature remains neutral with regard to jurisdictional claims in published maps and institutional affiliations.

\section{(c) (i)} adaptation, distr appropriate credit to the original author(s) and the source, provide a link to the Creative Commons license, and indicate if changes were made. The images or other third party material in this article are included in the article's Creative Commons license, unless indicated otherwise in a credit line to the material. If material is not included in the article's Creative Commons license and your intended use is not permitted by statutory regulation or exceeds the permitted use, you will need to obtain permission directly from the copyright holder. To view a copy of this license, visit http://creativecommons.org/ licenses/by/4.0/.

(C) The Author(s) 2021 